\title{
Article
}

\section{Synergistic anti-tumour potency of a self-assembling peptide hydrogel for the local co-delivery of doxorubicin and curcumin in the treatment of head and neck cancer}

Christina Karavasili, Dimitrios A Andreadis, Orestis L. Katsamenis, Emmanuel Panteris,

Pinelopi Anastasiadou, Zacharias Kakazanis, Vasilis Zoumpourlis, Catherine K.

Markopoulou, Sotirios Koutsopoulos, loannis S Vizirianakis, and Dimitrios G. Fatouros

Mol. Pharmaceutics, Just Accepted Manuscript • DOI: 10.1021/acs.molpharmaceut.8b01221 • Publication Date (Web): 26 Apr 2019

Downloaded from http://pubs.acs.org on May 2, 2019

\section{Just Accepted}

"Just Accepted" manuscripts have been peer-reviewed and accepted for publication. They are posted online prior to technical editing, formatting for publication and author proofing. The American Chemical Society provides "Just Accepted" as a service to the research community to expedite the dissemination of scientific material as soon as possible after acceptance. "Just Accepted" manuscripts appear in full in PDF format accompanied by an HTML abstract. "Just Accepted" manuscripts have been fully peer reviewed, but should not be considered the official version of record. They are citable by the Digital Object Identifier (DOI®). "Just Accepted" is an optional service offered to authors. Therefore, the "Just Accepted" Web site may not include all articles that will be published in the journal. After a manuscript is technically edited and formatted, it will be removed from the "Just Accepted" Web site and published as an ASAP article. Note that technical editing may introduce minor changes to the manuscript text and/or graphics which could affect content, and all legal disclaimers and ethical guidelines that apply to the journal pertain. ACS cannot be held responsible for errors or consequences arising from the use of information contained in these "Just Accepted" manuscripts. 


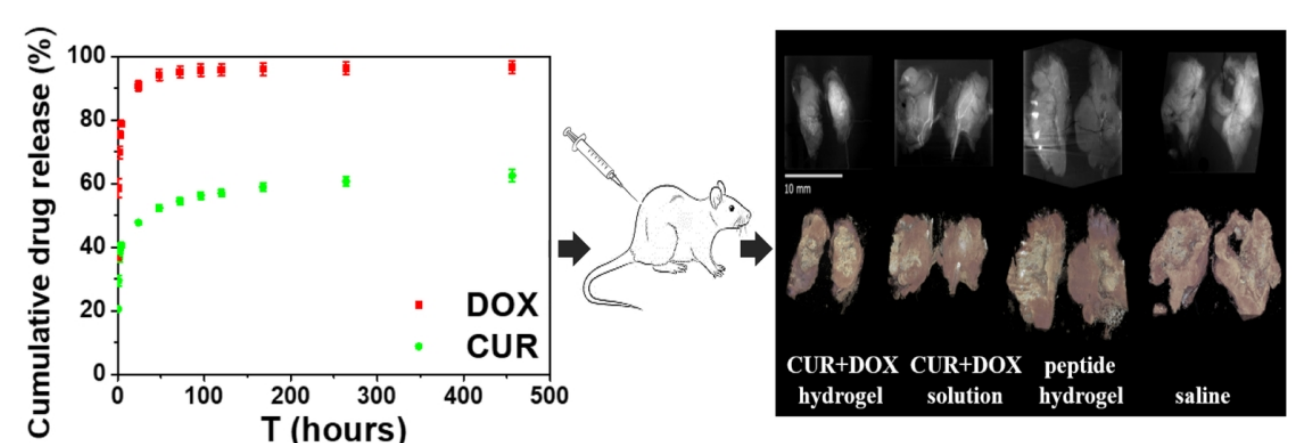

Graphical abstract

$564 \times 204 \mathrm{~mm}(72 \times 72$ DPI $)$ 


\title{
Synergistic anti-tumour potency of a self-
}

\author{
assembling peptide hydrogel for the local co-
}

\author{
delivery of doxorubicin and curcumin in the
}

\section{treatment of head and neck cancer}

\begin{abstract}
Christina Karavasili, ${ }^{\ddagger}$ Dimitrios A. Andreadis, ${ }^{ \pm}$Orestis L. Katsamenis, ${ }^{\#}$ Emmanuel Panteris, ${ }^{\natural}$ Pinelopi Anastasiadou, ${ }^{ \pm}$Zacharias Kakazanis," Vasilis Zoumpourlis," Catherine $K$. Markopoulou, ${ }^{\rfloor}$Sotirios Koutsopoulos, ${ }^{\S}$ Ioannis S. Vizirianakis, ${ }^{\circ}$ Dimitrios G. Fatouros ${ }^{\star *}$
\end{abstract}

${ }^{\ddagger}$ Department of Pharmaceutical Technology, School of Pharmacy, Aristotle University of Thessaloniki, GR-54124 Thessaloniki, Greece

${ }^{ \pm}$Department of Oral Medicine/Pathology, School of Dentistry, Aristotle University of Thessaloniki, GR-54124 Thessaloniki, Greece ${ }^{\#} \mu$-VIS X-ray Imaging Centre, Faculty of Engineering and the Environment, University of Southampton, SO17 1BJ, Southampton, UK IDepartment of Botany, School of Biology, Aristotle University of Thessaloniki, GR-54124 Thessaloniki, Greece

"National Hellenic Research Foundation, 11635 Athens, Greece ${ }^{\zeta}$ Laboratory of Pharmaceutical Analysis, Department of Pharmaceutical Technology, School of Pharmacy, Aristotle University of Thessaloniki, GR-54124 Thessaloniki, Greece ${ }^{\S}$ Center for Biomedical Engineering, Massachusetts Institute of Technology, 77 Massachusetts Avenue, Cambridge, MA 02139, USA 
${ }^{\circ}$ School of Pharmacy, Aristotle University of Thessaloniki, Department of Pharmacology, GR-54124 Thessaloniki, Greece 


\begin{abstract}
Combination therapy has been conferred with manifold assets leveraging the synergy of different agents to achieve sufficient therapeutic outcome with lower administered drug doses and reduced side effects. The therapeutic potency of a self-assembling peptide hydrogel for the co-delivery of doxorubicin (DOX) and curcumin (CUR) was assessed against head and neck cancer cells. The dual loaded peptide hydrogel enabled control over the rate of drug release based on drug's aqueous solubility. A significantly enhanced cell growth inhibitory effect was observed after treatment with the combination drug loaded hydrogel formulations compared to the respective combination drug solution. The synergistic pharmacological effect of selected hydrogel formulations was further confirmed with enhanced apoptotic cell response, interference in cell cycle progression and significantly altered apoptotic/anti-apoptotic gene expression profiles obtained in dose levels well below the half-maximal inhibitory concentrations of both drugs. The in vivo antitumour efficacy of the drug loaded peptide hydrogel formulation was confirmed in HSC-3 cell-xenografted SCID mice and visualized with $\mu \mathrm{CT}$ imaging. Histological and TUNEL assay analyses of major organs were implemented to assess the safety of the topically administered hydrogel formulation. Overall, results demonstrated the therapeutic utility of the dual drug-loaded peptide hydrogel as a pertinent approach for the local treatment of head and neck cancer.
\end{abstract}

Keywords: self-assembling peptide hydrogel, curcumin, doxorubicin, combination treatment, head and neck cancer

Abbreviations. CUR, curcumin; DOX, doxorubicin; $\mu \mathrm{CT}$, microfocus Computed Tomography; SCID, severe combined immunodeficient mice; CLSM, Confocal Laser Scanning Microscopy; PBS, Phosphate-buffered saline; CI, Combination Index; H\&E, 
Hematoxylin and Eosin; IC50, Half-maximal inhibitory concentration; HNSCC, Head and neck squamous cell carcinoma; FFPE, Formalin-fixed paraffin embedded.

\section{Introduction}

Head and neck squamous cell carcinomas (HNSCC) are malignant tumours that develop in or around the throat, larynx, nose, sinuses, and mouth, accounting for approximately 600,000 new cases annually, while the five-year overall survival rate of patients with HNSCC ranges between 40-50\%. ${ }^{1}$ The standard-of-care in HNSCC treatment includes combined modality therapy with surgical resection and concurrent radiotherapy, followed by chemotherapy. In cases of tumour recurrence and poor clinical response, chemotherapeutic protocols comprising single anticancer agents (cis-platin, carboplatin, fluorouracil) are optimized with the employment of targeted biological agents ${ }^{2}$ or combination chemotherapy ${ }^{3}$ aiming to potentiate the therapeutic outcome and enhance the clinical complete response and survival of patients with HNSCC.

The implementation of nutritional constituents, such as polyphenols, in cancer therapeutics, denoted as nutraceuticals, has been appraised for the prevention or adjuvant cancer therapy, encompassing multi-targeting efficacy and safety compared to the conventional toxic synthetic moieties. ${ }^{4}$ Curcumin, a plant-derived lipophilic polyphenol originating from the rhizomes of turmeric, has been broadly evaluated for its anti-oxidant, anti-inflammatory, as well as anticancer potential, modulating several biological pathways, thus affecting cell proliferation, mutagenesis, cell cycle progression, apoptosis, tumorigenesis, angiogenesis and metastasis. 5,6 The pleiotropic effects of curcumin at the molecular level are associated with its multifocal signal modulation properties. Its apoptotic efficacy against cancer cells has been shown to be p53-dependent, inducing mitochondrial cytochrome c release, with subsequent up-regulation of pro-apoptotic protein expression (e.g. Bax, Bak), inhibition of the import signaling pathways 
NF-kB, Akt/PI3K, and MAPK and decreased expression of multiple anti-apoptotic genes regulated by NF-אB (e.g. Bcl-2, Bcl-XL, cyclin D1, COX-2), increase in caspases (-3 and -9) activity and down-regulation of genes involved in tumour growth (e.g. c-myc), while its antiangiogenic properties are mediated through down-regulation of various proangiogenic proteins (e.g. VEGF) and inhibition of signal transduction pathways, such as those that involve the transcription factor NF- $\mathrm{KB}$ and protein kinase $\mathrm{C} .{ }^{7}$ A plethora of in vivo and in vitro studies have previously assessed the chemo-preventive and chemotherapeutic potency of curcumin in HNSCC treatment, either alone or in combinational therapeutic schemes. ${ }^{8}$

Conventional chemotherapeutic approaches employing intravenous systemic administration of cytotoxic agents are plagued by reduced bioavailability in the targeted tissue, rapid elimination and non-specific drug distribution, therefore resulting in serious systemic toxicity. In virtue of these unmet requirements, the necessity for efficient treatments featuring targeted drug delivery, control over drug release kinetics, improved drug solubility and minimization of systemic toxicity has been met with significant progress in the development of localized drug delivery systems. ${ }^{9}$ New therapeutic approaches in anticancer therapy encompass a wide range of injectable or implantable drug delivery platforms, classified on the basis of method of administration and the mechanism of action, including polymer nanoparticles, liposomes, and dendrimers or drug-eluting films, gels, wafers, rods and particles..$^{9}$ Injectable biodegradable hydrogels comprising of physical cross-linked hydrophilic polymers have generated considerable interest in biomedical applications. ${ }^{10}$ Among the several molecular building blocks of three-dimensional hierarchical hydrogel structures, self-assembling peptides are rendered as attractive candidates in injectable therapy, as a result of their biocompatible and biodegradable character and dynamically tunable properties. ${ }^{11,12}$ Self-assembling peptide hydrogels are able to undergo spontaneous gelation driven by inter- and intra-molecular noncovalent interactions (hydrophobic, electrostatic and hydrogen-bonding) in response to 
physiological stimuli ( $\mathrm{pH}$, temperature, ionic strength, light). ${ }^{13}$ Peptide hydrogels are featured as depot-based drug delivery systems enabling precise control over the directly encapsulated drug payload, controlled drug release profiles by regulating the mesh size of the entangled nanofiber network or by intervening in the meshwork's lipophilicity through changes in the peptide sequence, as well as appropriate shear thinning and mechanical properties for injectable therapies. ${ }^{14,15}$ In the current study, the ac-(RADA $)_{4}-\mathrm{CONH}_{2}$ peptide sequence has been utilized to evaluate its potency as carrier in a dual drug loaded delivery system against head and neck squamous cell carcinoma line. The ionic self-complementary 16-residue peptide, comprising alternating ionic and hydrophobic amino acids, has been extensively investigated, either functionalized or in its native form, in the multi-disciplinary field of biomedical applications, featuring tissue engineering, ${ }^{16-20}$ regenerative medicine, ${ }^{21-24}$ hemostasis $^{25}$ and biopharmaceuticals delivery applications. ${ }^{14,26-30}$

Combination chemotherapy is currently arising as a means to overcome multi-drug resistance and effectively enhance therapeutic response, while at the same reducing the administered drug dose and observed side effects, by utilizing the synergistic or additive effect of multiple anticancer agents in a co-delivery formulation. ${ }^{31-33}$ The incorporation of both curcumin and doxorubicin in a single delivery platform has been adopted as a co-delivery strategy in an attempt to improve antitumour efficacy, resulting in the development of diverse delivery systems including nanoparticles, ${ }^{34-37}$ micelles ${ }^{38-41}$ and liposomes. ${ }^{42}$ Combination therapy with dual-nanomedicines (nanoparticles, micelles, liposomes) both loaded with chemotherapeutic drugs has proven beneficial in enhancing antitumour efficacy, either by directly targeting tumour cells ${ }^{43-45}$ or the tumour micro-environment. ${ }^{46-48}$ Hydrogels have also shown great potential in localized combination drug therapy utilizing biodegradable and thermosensitive polymers $^{49}$ and polypeptides, ${ }^{50,51}$ peptide-drug conjugates $^{52}$ and peptide-polysaccharide composites, ${ }^{53}$ while at the same time incorporating drug-loaded nanogels, ${ }^{54}$ spherical 
vesicles, ${ }^{55}$ nanoparticles ${ }^{56}$ and micelles ${ }^{57}$ within the hydrogel to enable concurrent drug release and synergistic therapeutic efficacy. So far, no published data exist as to the potency of a selfassembling peptide hydrogel in dual drug treatment of head and neck cancer.

Herein, we report on the implementation of a self-assembling peptide hydrogel [ac-(RADA) 4- $^{-}$ $\left.\mathrm{CONH}_{2}\right]$ as carrier of a drug combination, namely curcumin and doxorubicin, against head and neck cancer cells. The current system enables precise control over the encapsulated drug payload, with drug aqueous solubility being the dictating factor over the rate of drug release. The drug combination hydrogel formulations were evaluated for their potency in exerting an apoptotic cell response and their synergistic antitumour mechanism was further assessed. The antitumour efficacy of the optimal formulation was evaluated in HSC-3 cell-xenografted SCID mice after intratumoural administration. $\mu \mathrm{CT}$ imaging of the tumour biopsies was utilized to provide valuable insights into tumour response after treatment by analyzing the morphological characteristics of the excised tumours. Overall, the findings of the current study suggest that self-assembling peptide hydrogels can be an expedient candidate for local combination therapy against head and neck cancer.

\section{Experimental Section}

Materials and cell culture. Phosphate-buffered saline 10X (PBS) was purchased from Gibco $^{\text {TM }}$ (Life Technologies, Grand Island, NY, USA). 3-(4,5-Dimethylthiazol-2-yl)-2,5diphenyltetrazolium bromide (MTT), dimethyl sulfoxide (DMSO), Triton X-100, curcumin and doxorubicin hydrochloride were purchased from Sigma-Aldrich Chemie Gmbh (Munich, Germany). ProLong® Gold Antifade Mountant with DAPI was purchased from ThermoFischer Scientific (Waltham, MA, USA). Peptide solution ac-(RADA $)_{4}-\mathrm{CONH}_{2}(1 \% \mathrm{v} / \mathrm{w})$ was purchased from PuraMatrix ${ }^{\circledR}$ (Corning, 221 NY, USA). 
HSC-3 oral squamous cell carcinoma cells were cultured in Dulbecco's modified eagle's medium (DMEM, Gibco ${ }^{\mathrm{TM}}$, Life Technologies, Grand Island, NY, USA) supplemented with $10 \%$ fetal bovine serum (FBS, Gibco ${ }^{\mathrm{TM}}$, Life Technologies, Grand Island, NY, USA) 100 units/mL Penicillin and $100 \mu \mathrm{g} / \mathrm{mL}$ Streptomycin $\left(\right.$ Gibco $^{\mathrm{TM}}$, Life Technologies, Grand Island, NY, USA). Cells were maintained at $37{ }^{\circ} \mathrm{C}$ in a humidified atmosphere with $5 \% \mathrm{CO}_{2}$. Exponentially growing cells were used in all studies.

Preparation of the drug loaded ac-(RADA) ${ }_{4}-\mathrm{CONH}_{2}$ peptide hydrogel. The dual drug loaded peptide hydrogel was prepared by initially dissolving DOX in the aqueous ac-(RADA) $4_{4}$ $\mathrm{CONH}_{2}$ solution of initial peptide concentration of $1 \% \mathrm{w} / \mathrm{v}$ (final DOX concentration: 5 $\mathrm{mg} / \mathrm{mL})$, followed by the addition of two microliters of CUR's solution $(5 \mathrm{mg} / \mathrm{mL})$ in ethanol (final drug concentration: $222 \mu \mathrm{g} / \mathrm{mL}$ ). The peptide solution was subjected to sonication until completely homogenized and gelation was initiated upon the addition of PBS to a final peptide concentration of $0.9 \% \mathrm{w} / \mathrm{v}$. The encapsulation efficiency of both drugs in the peptide hydrogel was $100 \%$.

\section{Drug localization within the peptide nanofiber hydrogel using confocal laser scanning} microscopy (CLSM). The spatial distribution of the fluorescent DOX and CUR within the ac$(\mathrm{RADA})_{4}-\mathrm{CONH}_{2}$ peptide nanofiber hydrogel was studied using CLSM. Z-stacks of the peptide hydrogel were acquired from its top to the equatorial plane with a Zeiss LSM 780 CLSM (Carl Zeiss Microscopy GmbH, Berlin, Germany) with a step size of $1.16 \mu \mathrm{m}$ using the $63 \times$ oil-immersion objective with the appropriate filters. Images acquisition was performed using the ZEN 2011 software. 


\begin{abstract}
Atomic force microscopy (AFM) studies. The nanofiber morphology before and after drug loading was visualized using a MultiMode Scanning Probe Microscope (Veeco) with a Nanoscope IIIa controller. The ac-(RADA) $)_{4}-\mathrm{CONH}_{2}$ solutions were diluted with MilliQ water to final peptide concentration of $0.01 \% \mathrm{w} / \mathrm{v}$ and $10 \mu \mathrm{L}$ aliquots were dropped onto the surface of freshly cleaved mica. After 30 seconds the surface was rinsed with $300 \mu \mathrm{L}$ MilliQ water and left to air-dry prior to imaging. The spring constant of the cantilever was $10 \mathrm{~N} / \mathrm{m}$ and height images were acquired with $1 \mathrm{~Hz}$ scanning rate.
\end{abstract}

In vitro release studies. In vitro release studies from the dual drug loaded peptide hydrogel were performed in acetate buffer $\mathrm{pH} 5.0$ and PBS pH 7.4 both containing $0.1 \% \mathrm{w} / \mathrm{v}$ Tween 80 at $37^{\circ} \mathrm{C} .{ }^{58,59}$ Dual drug loading was achieved as described in section 'Preparation of the drug loaded ac-(RADA $)_{4}-\mathrm{CONH}_{2}$ peptide hydrogel'. Gelation occurred after approximately $30 \mathrm{~min}$ from the addition of appropriate volume of PBS in the peptide solution. Then, $1 \mathrm{~mL}$ of release medium was gently added on top of the hydrogel and samples $(800 \mu \mathrm{L})$ were periodically withdrawn and replaced with $800 \mu \mathrm{L}$ of fresh and preheated medium. The mechanism of drug release was evaluated after fitting the first $60 \%$ of the experimental release data to KorsmeyerPeppas equation. ${ }^{60}$ DDSolver was the software used for the kinetic analysis of the experimental data. ${ }^{61}$

Drug quantification in the binary samples. CUR and DOX quantification in the binary samples was performed using the first derivative of the ratio spectra UV spectrophotometric method. A Shimadzu UV-Vis double beam Spectrophotometer (UV-2501 PC model) consisting of a double monochromator and a light source of a $50 \mathrm{~W}$ halogen and a deuterium lamp was used. Spectrophotometric measurements were performed using the following 
conditions: scan speed $210 \mathrm{~nm} / \mathrm{min}$, slit width $1.0 \mathrm{~nm}$ and sampling interval $0.1 \mathrm{~nm}$. The UVPC Personal Spectroscopy software was used.

Rheological characterization. Rheological measurements were performed using a rotational rheometer (Physica MCR 300, Physica Messtechnic GmbH, Stuttgart, Germany) with a coneplate geometry and a truncation of $0.05 \mathrm{~mm}$. The cone was $25 \mathrm{~mm}$ in diameter with a cone angle of $1^{\circ}$. A Paar Physica circulating bath and a controlled Peltier system (TEZ 150P/MCR) were used for temperature regulation at $37 \pm 0.1^{\circ} \mathrm{C}$. The plain or dual drug loaded peptide solution $(600 \mu \mathrm{L})$ were loaded on the rheometer plate and were hydrated with PBS pH 7.4 to a final peptide concentration of $0.9 \% \mathrm{w} / \mathrm{v}$. A solvent trap was used to ensure that no evaporation occurs during measurements and measurements were initiated immediately after buffer addition. Oscillatory time sweeps were performed at a constant strain of $0.5 \%$ and frequency of $1 \mathrm{~Hz}$. Frequency sweep tests were performed at $0.5 \%$ strain and over the range of $0.1-100$ Hz. Strain was kept within the linear viscoelastic regime. Data analysis was performed using the software US200 V2.21.

Cell proliferation assay-Determination of $\mathbf{I C}_{\mathbf{5 0}}$ values. The MTT assay was used to assess the effect of drug solutions and drug loaded peptide hydrogels on HSC-3 cell proliferation. The cells were plated in 96-well plates $\left(5 \cdot 10^{3}\right.$ cells/well $)$ and after $24 \mathrm{~h}$ they were exposed to fresh medium containing the drug solutions (CUR: 0.1, 1, 2.5, 5, 10, 25, 50, $100 \mu \mathrm{M}$, DOX: 0.05, $0.1,0.125,0.25,0.5,1,2.5,10 \mu \mathrm{M})$ or the drug- loaded peptide hydrogels of equivalent drug concentrations (peptide hydrogel-CUR: $0.1,1,2.5,5,10,25,50,100 \mu \mathrm{M}$, peptide hydrogelDOX: $0.05,0.1,0.125,0.25,0.5,1,2.5,10 \mu \mathrm{M})$. After $48 \mathrm{~h}$ incubation, the MTT solution (10 $\mu \mathrm{L}, 5 \mathrm{mg} / \mathrm{mL}$ ) was added to each well followed by incubation for $4 \mathrm{~h}$ in a humidified atmosphere at $37{ }^{\circ} \mathrm{C}$. The supernatants were removed and $100 \mu \mathrm{L}$ of dimethyl sulfoxide 
(DMSO) were added to dissolve the formed formazan crystals. The absorbance was measured at $570 \mathrm{~nm}$ using an ELISA plate reader. The $\mathrm{IC}_{50}$ values were calculated from the linear regression line of the plot of percentage inhibition versus log inhibitory concentration using the sigmoidal dose response equation (variable slopes) (Table 1).

Cell proliferation assay-Determination of combination indices (CI). Drug combination studies were performed to calculate the CI values of the different solution DOX+CUR and peptide hydrogel-DOX+CUR combinations. HSC-3 cells were plated in 96 -well plates $\left(5 \cdot 10^{3}\right.$ cells/well). After $24 \mathrm{~h}$, the cells were exposed to fresh culture medium containing free CUR (1, $5,10,15 \mu \mathrm{M})$ and DOX $(0.05,0.1,0.2,0.4,0.6 \mu \mathrm{M})$ or peptide hydrogel-CUR $(1,5,10,15$ $\mu \mathrm{M})$ and peptide hydrogel-DOX $(0.05,0.1,0.16,0.4,0.6 \mu \mathrm{M})$ individually and in combination for $48 \mathrm{~h}$. Untreated cells were used as the control. Cell proliferation was also evaluated in the presence of the peptide hydrogel. Following incubation for $48 \mathrm{~h}$, cell growth was evaluated using the MTT assay, as previously described, according to Equation 1 (Figure 3):

$$
\text { Cell growth }(\% \text { of control })=\left(\mathrm{OD}_{\text {test }}-\mathrm{OD}_{\text {blank }}\right) /\left(\mathrm{OD}_{\text {control }}-\mathrm{OD}_{\text {blank }}\right) \times 100
$$

Combination indices were calculated using the CompuSyn software Version 1.0.

Apoptosis assay by flow cytometry. Cell apoptosis in HSC-3 cells was evaluated using flow cytometry after cell staining with Annexin-V-FITC/Propidium iodide (PI), according to manufacturer's instructions (BioLegend, San Diego, CA). HSC-3 cells were plated in 6-well plates $\left(1 \times 10^{6}\right.$ cells/well $)$. After $24 \mathrm{~h}$, the culture medium was replaced with fresh medium containing the chosen optimal drug combinations. Untreated cells were used as the control. After treatment for $24 \mathrm{~h}, 48 \mathrm{~h}$ and $72 \mathrm{~h}$, the cells were harvested, washed twice with ice-cold PBS and re-suspended in $100 \mu \mathrm{L}$ of Annexin-V binding buffer at a concentration of $1 \times 10^{6}$ cells/mL. Cells were then stained with $5 \mu \mathrm{L}$ Annexin-V-FITC and $10 \mu \mathrm{L}$ PI for $15 \mathrm{~min}$ at room 
temperature in the dark, prior to flow cytometry measurements. A total of 20,000 events was collected per sample using CyFlow ${ }^{\circledR}$ Cube 8 (Sysmex Partec GmbH, Goerlitz, Germany).

Detection of apoptosis-DAPI staining. Detection of apoptotic features related to morphological changes in cell nuclei were visualized using CLSM. HSC-3 cells were seeded on coverslips in 6-well plates. After $24 \mathrm{~h}$, the cells were exposed to the combination formulations for $6 \mathrm{~h}, 12 \mathrm{~h}$ and $24 \mathrm{~h}$. After the specified time-points, the cells were washed with 1x PBS, fixed in $4 \%(\mathrm{w} / \mathrm{v})$ PFA (in PBS, $15 \mathrm{~min}$ ) and permeabilized in $1 \%(\mathrm{v} / \mathrm{v})$ Triton-X for $10 \mathrm{~min}$ at room temperature with additional intermediate steps of washing with PBS, prior to coverslip mounting onto glass microscope slides using Prolong Gold Antifade Reagent with DAPI. The specimens were examined with a Zeiss LSM780 CLSM (Carl Zeiss Microscopy $\mathrm{GmbH}$, Berlin, Germany) using the $40 \times$ oil-immersion objective with the appropriate filters. Images acquisition was performed using the ZEN 2011 software.

Cell cycle analysis. Cell cycle analysis was performed using flow cytometry by measuring the cellular DNA content after PI staining. HSC-3 cells were plated at 6 -well plates $\left(5 \cdot 10^{5}\right.$ cells/well) and were left overnight to attach. The cells were then synchronized after serum deprivation for $24 \mathrm{~h}$ and were subsequently incubated with the combination formulations for 6 h, $12 \mathrm{~h}$ and $24 \mathrm{~h}$. After the specified time-points, cells were harvested and fixed in $70 \%$ ethanol overnight at $4{ }^{\circ} \mathrm{C}$. The DNA content was measured using the CyStain PI absolute T kit (Partec, Münster, Germany) according to the manufacturer's guidelines. Analysis was performed using CyFlow Cube 8 (Partec) and 40,000 events were recorded. Cell cycle distribution was analyzed using the FCS Express 4 (De Novo software, Los Angeles, CA). 
Real-Time qPCR analysis. HSC-3 cells were plated in $100 \mathrm{~mm}$ tissue culture dishes $\left(10^{6}\right.$ cells/plate) and were left overnight to attach. After $24 \mathrm{~h}$ the cells were exposed to the selected combination formulations. After treatment for $24 \mathrm{~h}$, the cells were harvested, and total RNA was isolated using the Nucleospin ${ }^{\circledR}$ RNA/Protein kit (Macherey-Nagel, Germany). RNA samples were subjected to reverse transcription using the QuantiTect ${ }^{\circledR}$ Reverse Transcription Kit (Qiagen Inc., Chatsworth, CA, USA) as per manufacturer's instructions. Quantitative RTPCR analysis was performed using the KAPA SYBR ${ }^{\circledR}$ FAST Master Mix (2X) Universal (Kapa Biosystems, USA). The primer sequences used are listed in Table S1. Data normalization was based on the expression of the housekeeping gene, $\beta$-actin. Real Time qPCR experiments were run in triplicates.

\begin{abstract}
Animals. Eight-week-old female SCID mice weighting 18-20 g were purchased from Charles Rivers Laboratories (Lyon, France). Animals were bred under pathogen-free conditions. All mice were reared with food and water ad libitum in a $12 \mathrm{~h}$ dark $/ 12 \mathrm{~h}$ light cycle. The in vivo experimental protocol was approved by the Institutional Bioethics Committee for Animal Experimentation. Power analysis was performed using the $\mathrm{G}^{*}$ Power software.

Experiments were conducted in the authorized animal facilities of the National Hellenic Research Foundation and complied with the Protocol on the Protection and Welfare of Animals, the regulations of the National Bioethics Committee and the article 3 of the presidential decree 160/1991 (in line with 86/609/EEC directive), regarding the protection of experimental animals.
\end{abstract}

In vivo antitumour efficacy in HSC-3 xenograft mouse model. The in vivo antitumour efficacy of the dual drug loaded peptide hydrogel containing CUR and DOX in the selected molar concentration ratio ( $1 \mu \mathrm{M}$ CUR $+0.164 \mu \mathrm{M}$ DOX) was tested in HSC-3 tumour 
xenografted mice. HSC-3 cells $\left(10^{6}\right.$ cells/mouse, $\left.100 \mu \mathrm{L}\right)$ were injected subcutaneously in the right flank of female SCID mice. Once tumour volume reached ca. $120 \mathrm{~mm}^{3}$ at approximately 3 weeks after tumour inoculation (day 0), mice were weighted and randomly divided into four groups (four mice per group): (A) normal saline (control), (B) ac-(RADA) ${ }_{4} \mathrm{CONH}_{2}$ peptide hydrogel (blank), (C) DOX+CUR saline solution at a total DOX dose of $20 \mathrm{mg} / \mathrm{kg}$ and (D) DOX+CUR ac-(RADA) ${ }_{4} \mathrm{CONH}_{2}$ peptide hydrogel at a total DOX dose of $20 \mathrm{mg} / \mathrm{kg}$. The mice were administered intratumourally with $100 \mu \mathrm{L}$ of each treatment on days $0,4,8$ and 12 using a 1.0-mL syringe. Tumour volumes and body weights were monitored every three days. Tumour volume was measured using a digital caliper and calculated according to equation: Tumour volume $=\mathrm{L} \times \mathrm{W} \times \mathrm{H} \times \pi / 6$, where $\mathrm{L}$ is the long diameter, $\mathrm{W}$ is the short diameter and $\mathrm{H}$ is the tumour height. Body weight change was monitored to evaluate treatment toxicity.

\section{In vivo toxicity evaluation}

Organ-to-body weight ratios. Organ weight has been designated as a sensitive indicator of the effect of an experimental treatment, even in the absence of any histological findings. Therefore, the organ-to-body weight ratios were determined to assess the potential organ specific toxicity of the treatments. At the end of the study, the body and organ weights were individually measured, and the organ index was calculated by the endpoint organ-to-body weight ratio.

Histological evaluation. At the end of the experiment (day 15), animals were euthanized and tumours and major organs (heart, liver, spleen and kidney) were dissected, individually weighted, fixed with $4 \%$ paraformaldehyde in PBS and embedded in paraffin (FFPE). Tumour and organs were cut in half and across the mid-line. Four $5 \mu \mathrm{m}$-thick-sections were removed, stained with H\&E (hematoxylin and eosin) and observed under a light microscope (Olympus 
CX31 optical microscope). Images were acquired using the OLYMPUS analySIS getIT software.

\section{D X-ray histological evaluation by means of microfocus Computed Tomography $(\mu C T)$.} Upon completion of conventional histological evaluation characterization (sectioning, H\&E staining, and light microscopy), four randomly selected FFPE tumour specimens were further analyzed by state-of-the-art $\mu \mathrm{CT}$ (Med-X prototype micro-CT scanner; Nikon Metrology UK Ltd). This first-of-kind $\mu \mathrm{CT}$ scanner is optimized for producing diagnostic-quality conventional $\mu \mathrm{CT}$ imaging (i.e. X-ray absorption-based) of soft tissues and was the result of a collaborative project between $\mu$-VIS X-Ray imaging Centre at the University of Southampton and Nikon X-Tek Systems Ltd.

FFPE tumour tissue blocks were mechanically detached from their respective plastic cassettes (blocks were not de-waxed) and then placed onto sample holders for scanning. The specimens were imaged with the beam conditions set at follows: Acceleration voltage $=55 \mathrm{kVp}$; X- ray tube current $=131 \mu \mathrm{A}$; no beam filtration; source-to-object distance $=44.6 \mathrm{~mm}$; source-todetector distance $=992.0 \mathrm{~mm}$. The latter two distances resulted in an isotropic voxels size of 9 $\mu \mathrm{m} .2501$ projections were collected over an angular range of 360 degrees and 4 frames were averaged per projection to improve SNR. Integration time per projection was set to $2 \mathrm{~s}$ and the detector's analogue gain to $24 \mathrm{~dB}$. Upon completion of the acquisition, the acquired radiographs were reconstructed to 32-bit raw files using the scanner's build-in reconstruction software (Nikon, CT Agent, v. XT 5.1.4.2 MedX 1; Nikon X-Tek Systems Ltd, Tring, UK), by means of filtered-back projection. The raw 32-bit volume files were then converted to 16-bit volumes for visualization and 8-bit for image-based qualification. 
$\boldsymbol{\mu C T}$ image processing and qualification. For image processing and quantification, a range of software was used depending on the nature of the task. 3D semi-automatic segmentation was carried out in ITK-snap (v. 3.8.0 -alpha), an open source software medical image processing platform focusing on segmentation and analysis of 2D and 3D datasets using snake evolution algorithms. ${ }^{62}$ Tumour segmentation (i.e. separation of biopsy material from the surrounding wax matrix; Figure S3A) was performed using the thresholding method for calculating the region competition feature image followed by manual seeding. Necrotic areas located in the core of the tumours (Figure S3B) were segmented using classifiers which were previously trained to discriminate between necrotic tissue, tumour tissue, wax and air. The training was done by manually selecting representative regions from each "class" of features. Finally, calcifications within the necrotic areas were segmented using the thresholding method described earlier for the segmentation of the whole tumour tissue (Figure S3C). Visualization was carried out in Fiji/ImageJ and Avizo (v 9.3.0, FEI / Thermo Fisher Scientific).

Post- $\mu$ CT imaging Histology. Following $\mu \mathrm{CT}$, the wax biopsy blocks were reattached on to histology cassettes without de-waxing the tissue, so that the registration between the $\mu \mathrm{CT}$ and the histology slices was preserved. Two $4 \mu \mathrm{m}$-thick tissue sections were cut from each tumour sample and mounted onto microscope slides following standard protocols. The sections were then deparaffinised and stained using $2 \%$ aqueous Alizarin Red to stain and visualise mineral deposits. ${ }^{63}$

The histological sections were scanned using an Olympus VS110 virtual microscopy system equipped with a 10x objective, digitized using Olympus VS Desktop software (v2.9) and saved in Olympus native .vsi file format. 
TUNEL assay. The histological tumour and heart sections were deparaffinized and stained for apoptosis by the terminal deoxynucleotidyl transferase (TdT)-mediated dUTP nick end labeling (TUNEL) using the Click-iT ${ }^{\mathrm{TM}}$ Plus TUNEL Assay kit for in situ apoptosis detection with Alexa Fluor ${ }^{\mathrm{TM}} 488$ dye (ThermoFischer Scientific, Waltham, MA, USA), according to the manufacturer's instructions. Cell nuclei were stained with Prolong Gold Antifade Reagent with DAPI. The specimens were examined with a Zeiss LSM780 CLSM with a 40x oil-immersion lens. Images were acquired with ZEN2011 software.

Statistical analysis. All data are presented as means \pm standard deviation (SD). The data were analyzed using t-tests and Anova with the significance level set at 0.05 . Tukey post hoc analysis was used to evaluate statistically significant differences between groups.

\section{Results and discussion}

Effect of drug localization within the peptide hydrogel on the in vitro drug release. In vitro release studies of DOX and CUR from the peptide hydrogel were conducted in PBS pH 7.4 and acetate buffer $\mathrm{pH} 5.0$ at $37^{\circ} \mathrm{C}$. A correlation between drugs' aqueous solubility and the rate of drug release was recognized, suggesting the development of host-guest interactions between the active moieties and the peptide nanofibers of the hydrogel meshwork. The relation between the aqueous solubility of multiple small molecule drugs and the rate of drug release from multidomain peptide hydrogels has been recently studied, ${ }^{64}$ showing that the less hydrophilic molecules are expected to localize in the intrafibrillar hydrophobic core, hence demonstrating prolonged release profiles, in contrast to the burst release of the hydrophilic ones mainly distributed in the surrounding aqueous hydrogel environment. This pattern is clearly illustrated in Figure 1A with the distinctive localization of the water insoluble CUR within the hydrophobic domains of the peptide nanofibers, whereas no distinctive signal is acquired for 
the water-soluble doxorubicin, suggesting no specific intrafibrillar interaction. AFM analysis revealed that the self-assembling peptide retained its ability to form nanofibers even after drug loading as shown in figure S1. The differential drug distribution within the nanofiber matrix is also depicted on the rate of drug release (Figure 1B), with the hydrophilic DOX achieving 80 $\%$ release within the first four hours, while $40 \%$ of CUR was released at the same timeframe in PBS pH 7.4. A plateau was achieved for DOX after $24 \mathrm{~h}$ with almost total drug release, while CUR demonstrated a more sustained release profile over 19 days (62\% total drug release). In vitro release studies of DOX and CUR were also performed in acetate buffer $\mathrm{pH} 5.0$ simulating the acidic tumour microenvironment (Figure S2). No statistically significant differences were observed for the release of both drugs between $\mathrm{pH} 5.0$ and $\mathrm{pH} 7.4$, suggesting that the $\mathrm{pH}$ of the release medium has no profound effect on drug interaction with the peptide nanofibers and therefore on the rate of drug release form the hydrogel matrix. The drug release data were fitted to the Korsmeyer-Peppas equation showing good linearity for both CUR $\left(\mathrm{R}^{2}=0.917\right)$ and $\operatorname{DOX}\left(\mathrm{R}^{2}=0.928\right)$. The exponent of $\mathrm{n}$ was calculated to be 0.469 for $\mathrm{CUR}\left(\mathrm{K}_{\mathrm{H}}=7.741\right)$ and 0.141 for DOX $\left(\mathrm{K}_{\mathrm{H}}=16.573\right)$ indicative of non-Fickian transport for CUR and Fickian diffusion for DOX.

Rheological characterization of the peptide hydrogel drug carrier. The gelation kinetics and mechanical rigidity of the hydrogel samples were monitored using oscillatory time sweep experiments. Both plain and dual drug loaded samples showed a similar gelation kinetic pattern with the initial lag phase ending at approximately $20 \mathrm{~min}$ post initiation of the gelation process, followed by a rapid growth phase within the next $10 \mathrm{~min}$. For both samples storage modulus was an order of magnitude higher than loss modulus throughout the experiment [Figure 1C (a)], indicative of a gel structure. Frequency sweep tests revealed a dominant elastic solid-like behavior for both hydrogel samples with G' and G', being nearly independent of frequency. 
However, incorporation of both DOX and CUR in the peptide carrier seems to impact peptide nanofiber network mechanics, inducing a decrease in hydrogel rigidity as indicated by the higher G' values obtained for the plain peptide hydrogel [Figure 1C (b)]. Similar observations have been previously reported after DOX loading in ac-(RADA) $)_{4}-\mathrm{CONH}_{2}$, suggesting that the dual drug load interferes with the self-assembling process of the peptide nanofibers, modulating interfibrillar interactions that lead to the formation of an entangled nanofiber network. ${ }^{65}$ 
A

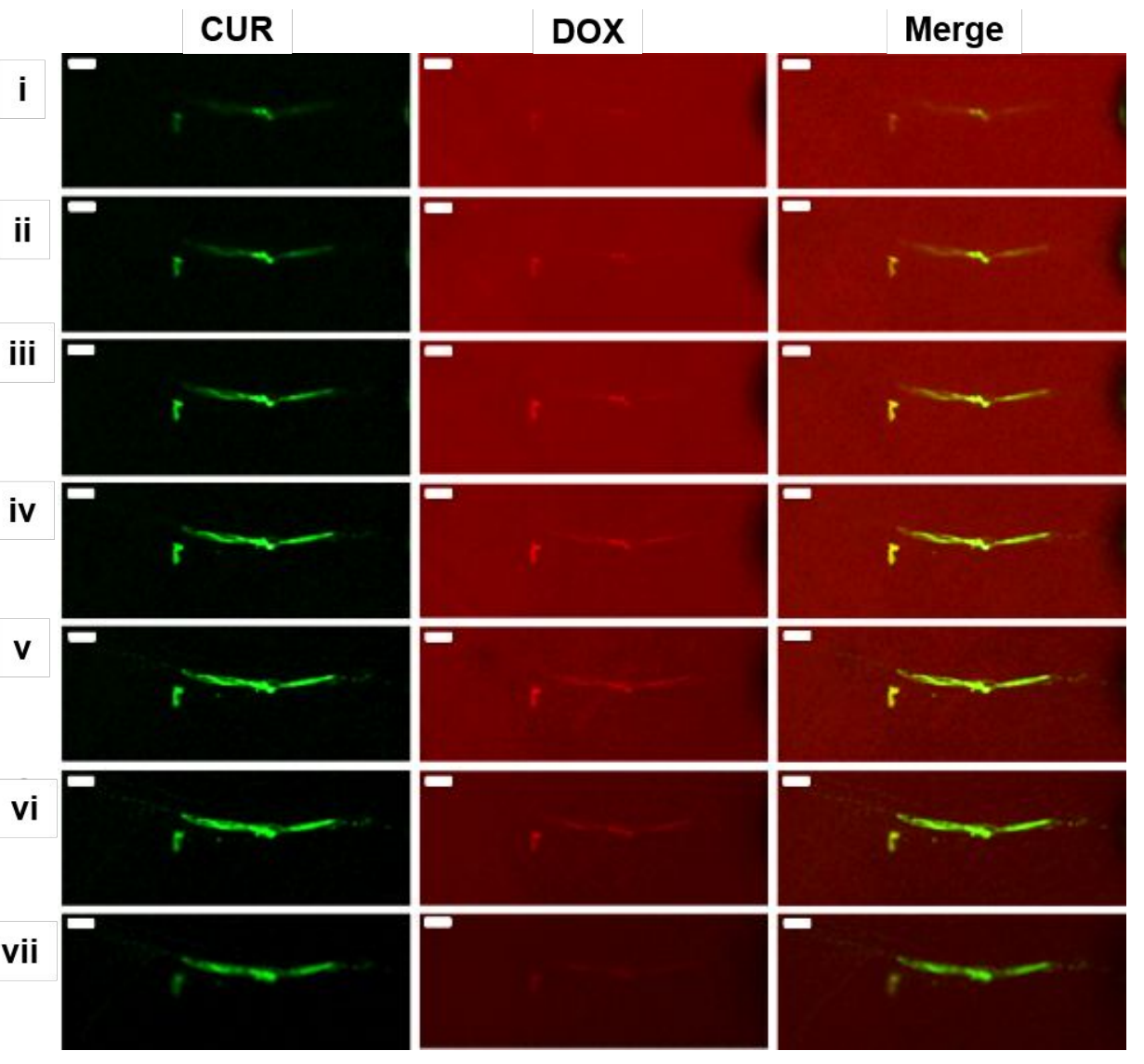

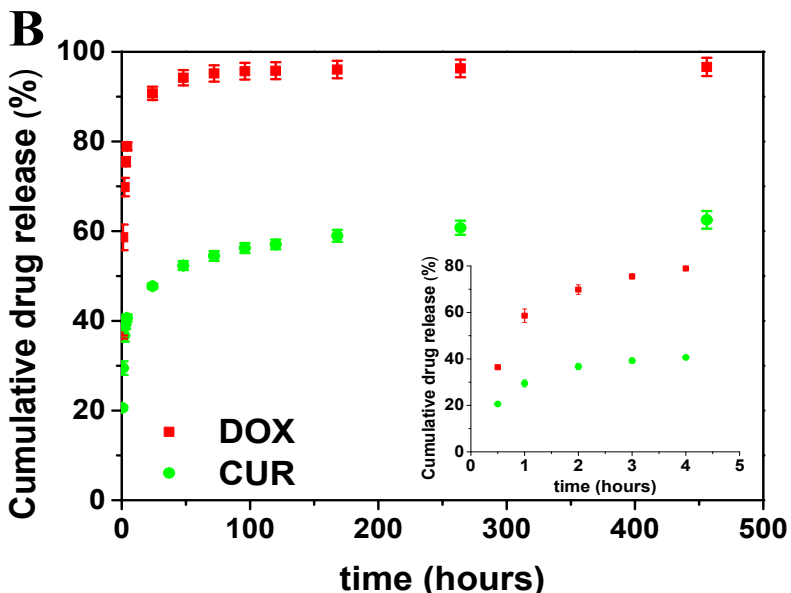
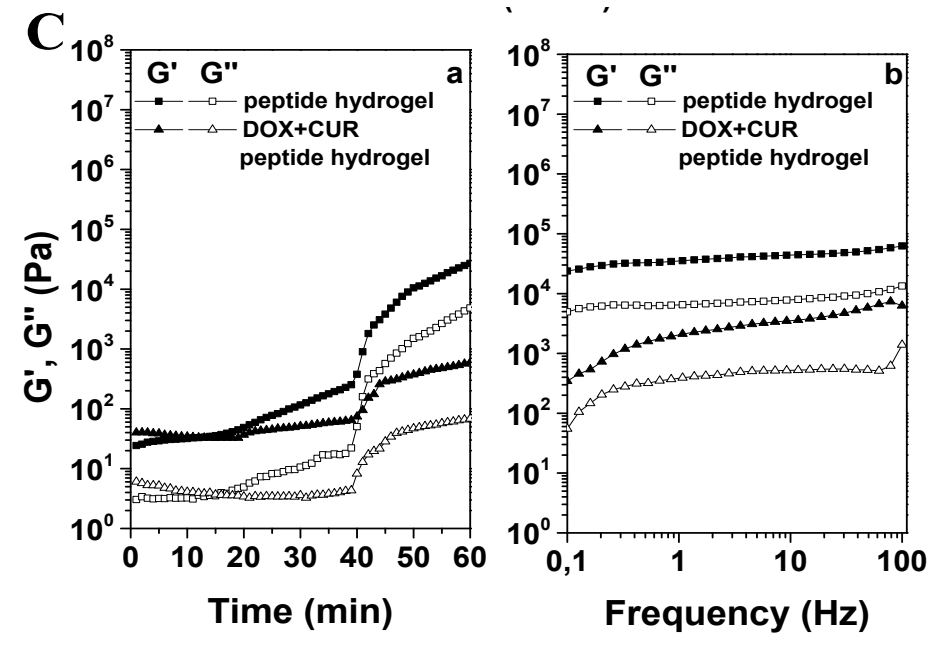
Figure 1. A. CLSM (63x objective) z-stack images of CUR (green) and DOX (red) loaded-ac$(\mathrm{RADA})_{4}-\mathrm{CONH}_{2}$ peptide nanofiber hydrogel. Scale bar: $10 \mu \mathrm{m}$. B. In vitro release profiles of CUR and DOX from the dual drug-loaded peptide hydrogel conducted in PBS $(0.1 \%$ Tween 80) $\mathrm{pH} 7.4$ at $37^{\circ} \mathrm{C}(\mathrm{n}=3, \pm$ S.D.). Inset represents drug release data for the first four hours. $\mathbf{C}$. Characterization of the rheological properties of the plain and dual drug loaded peptide hydrogel with (a) oscillatory time sweep measurements performed at a constant strain of $0.5 \%$ and frequency of $1 \mathrm{~Hz}$ and (b) frequency sweep tests performed at $0.5 \%$ strain and over the frequency range of 0.1-100 Hz.

In vitro cell growth inhibition assay. The anti-proliferative effect of CUR and DOX in solution and the drug loaded ac-(RADA) ${ }_{4}-\mathrm{CONH}_{2}$ peptide hydrogel, individually and in combination was evaluated in HSC-3 cultures after cell treatment for $48 \mathrm{~h}$. Cell exposure to individual treatments resulted in a dose-dependent cell growth inhibition (Figure S4) with the respective half maximal inhibitory concentrations $\left(\mathrm{IC}_{50}\right)$ reported in Table 1 . Similar $\mathrm{IC}_{50}$ values for both CUR and DOX have also been previously reported in a head and neck squamous cell carcinoma line. ${ }^{66}$ The peptide hydrogel loaded CUR exhibited an equivalent to plain CUR solution $\mathrm{IC}_{50}$ value, while for the peptide hydrogel loaded DOX a significantly higher inhibitory effect was achieved with a 2.4 -fold reduction in $\mathrm{IC}_{50}$, compared to plain $\mathrm{DOX}$ solution $(\mathrm{P}<0.001)$, increasing cell susceptibility to DOX treatment. 
Table 1. Half maximal inhibitory concentrations $\left(\mathrm{IC}_{50}\right)$ of the drug solutions and the drug loaded ac-(RADA) $)_{4}-\mathrm{CONH}_{2}$ peptide hydrogels in HSC-3 cells $(n=4, \pm$ S.D.).

\begin{tabular}{cc}
\hline Drug & IC $_{\mathbf{5 0}}(\boldsymbol{\mu M})( \pm$ S.D. $)$ \\
\hline CUR solution & $10.8( \pm 1.44)$ \\
DOX solution & $0.4( \pm 0.05)$ \\
peptide hydrogel-CUR & $10.1( \pm 4.91)$ \\
peptide hydrogel- DOX & $0.164( \pm 0.01)$ \\
\hline
\end{tabular}

Based on the calculated $\mathrm{IC}_{50}$ values of the individual treatments, a concentration range of CUR and DOX in solution form or embedded in the ac-(RADA) $)_{4}-\mathrm{CONH}_{2}$ hydrogel was evaluated for their combined inhibitory effect on cell growth. It is well documented from the doseresponse graphs (Figure S5), that the dual drug loaded peptide hydrogel exerts a significantly higher anti-proliferative effect on HSC-3 cells in the majority of combination concentrations evaluated, compared to the respective solution combinations. This is further exemplified in Table 2, where the CI values for the solution combinations denote antagonism for all the low CUR concentrations ( $1 \mu \mathrm{M}$ and $5 \mu \mathrm{M})$, while synergism is only achieved at the higher CUR concentrations [10 $\mu \mathrm{M}$ (only for DOX doses above $4 \mu \mathrm{M}$ ) and $15 \mu \mathrm{M}]$. On the contrary, a fortuitous synergistic effect was observed for all dual drug loaded peptide hydrogel formulations, with the effect being more pronounced even at the lower CUR and DOX concentrations, well below the $\mathrm{IC}_{50}$ values of the individual hydrogel loaded drugs (Table 3 ). Results profoundly indicate the potency of the dually loaded peptide hydrogel over the drug solution combinations to suppress cell proliferation. The following combination formulations were selected for further evaluation; peptide hydrogel ( $1 \mu \mathrm{M}$ CUR $+0.164 \mu \mathrm{M}$ DOX), peptide 
hydrogel $(10 \mu \mathrm{M}$ CUR $+0.6 \mu \mathrm{M}$ DOX) and solution $(10 \mu \mathrm{M}$ CUR $+0.4 \mu \mathrm{M}$ DOX). No effect on cell proliferation was observed in the presence of the ac-(RADA) $)_{4}-\mathrm{CONH}_{2}$ hydrogel (Figure $\mathrm{S} 5 \mathrm{~B}$ ), indicating that the cytotoxicity of the drug-loaded peptide hydrogel formulations is not due to the hydrogel carrier.

Table 2. Combination indices of different drug dose combinations in solution form and their effect of interaction graded in symbols. ${ }^{67}$ Symbols denote: (-----/+++++) Very strong antagonism/synergism, $\quad(----/++++) \quad$ Strong antagonism/synergism, $\quad(---/+++)$ antagonism/synergism, (--/++) moderate antagonism/synergism, (-/+) slight antagonism/synergism, $( \pm)$ nearly additive.

\begin{tabular}{cccc}
\hline $\begin{array}{c}\text { Drug concentration }(\boldsymbol{\mu M}) \\
\text { Dorcumin }\end{array}$ & Doxorubicin & CI & Grading symbol \\
\hline \multirow{4}{*}{1} & 0.05 & 1.62 & --- \\
& 0.1 & 1.29 & -- \\
& 0.2 & 1.04 & \pm \\
& 0.4 & 1.26 & -- \\
0.6 & 1.16 & - \\
\hline & 0.05 & 1.66 & --- \\
5 & 0.1 & 1.90 & -- \\
& 0.2 & 1.45 & -- \\
& 0.4 & 1.61 & --- \\
& 0.6 & 1.33 & -- \\
\hline \multirow{2}{*}{10} & 0.05 & 1.07 & \pm \\
& 0.1 & 1.00 & \pm \\
& 0.2 & 0.90 & +++ \\
& 0.4 & 0.42 & +++ \\
\hline & 0.6 & 0.58 & +++ \\
& 0.05 & 0.34 & +++ \\
& 0.1 & 0.68 & ++++ \\
& 0.2 & 0.12 & +++ \\
& 0.4 & 0.51 & + \\
\hline
\end{tabular}


Table 3. Combination indices of the different ac-(RADA $)_{4}-\mathrm{CONH}_{2}$ peptide hydrogel loaded drug dose combinations and their effect of interaction graded in symbols. ${ }^{67}$ Symbols denote: (-----/+++++) Very strong antagonism/synergism, (----/++++) Strong antagonism/synergism, $(---/+++)$ antagonism/synergism, (--/++) moderate antagonism/synergism, (-/+) slight antagonism/synergism, $( \pm)$ nearly additive.

\begin{tabular}{|c|c|c|c|}
\hline \multicolumn{2}{|c|}{ Drug concentration $(\mu \mathrm{M})$} & \multirow{2}{*}{ CI } & \multirow{2}{*}{ Grading symbol } \\
\hline ac-(RADA) $)_{4}-\mathrm{CONH}_{2}-\mathrm{CUR}$ & ac-(RADA) $)_{4}-\mathrm{CONH}_{2}-\mathrm{DOX}$ & & \\
\hline \multirow{5}{*}{ 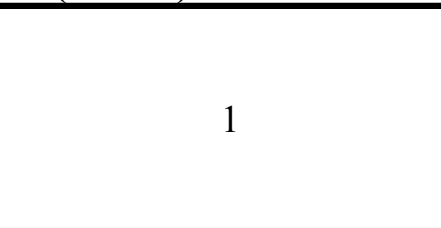 } & 0.05 & 0.53 & +++ \\
\hline & 0.1 & 0.52 & +++ \\
\hline & 0.164 & 0.48 & +++ \\
\hline & 0.4 & 0.57 & +++ \\
\hline & 0.6 & 0.74 & ++ \\
\hline \multirow{5}{*}{5} & 0.05 & 0.67 & +++ \\
\hline & 0.1 & 0.76 & ++ \\
\hline & 0.164 & 0.73 & ++ \\
\hline & 0.4 & 0.56 & +++ \\
\hline & 0.6 & 0.73 & ++ \\
\hline \multirow{5}{*}{10} & 0.05 & 0.82 & ++ \\
\hline & 0.1 & 0.79 & ++ \\
\hline & 0.164 & 0.70 & ++ \\
\hline & 0.4 & 0.79 & ++ \\
\hline & 0.6 & 0.56 & +++ \\
\hline \multirow{5}{*}{15} & 0.05 & 0.50 & +++ \\
\hline & 0.1 & 0.20 & ++++ \\
\hline & 0.164 & 0.55 & +++ \\
\hline & 0.4 & 0.41 & +++ \\
\hline & 0.6 & 0.50 & +++ \\
\hline
\end{tabular}

Apoptotic effect of combination formulations on HSC-3 cells. The cytotoxic effect of the combination formulations on HSC-3 cells was evaluated using a flow cytometric apoptosis assay (Annexin V-FITC/PI) after cell treatment for $24 \mathrm{~h}, 48 \mathrm{~h}$ and $72 \mathrm{~h}$ (Figure 2A). A considerable time-dependent increase in the late-stage apoptotic cell population was evidenced in all cases (Figure 2B). The most prominent apoptotic effect on HSC-3 cells was induced by the $(10 \mu \mathrm{M}$ CUR $+0.6 \mu \mathrm{M}$ DOX) peptide hydrogel formulation with an early onset of action (24 h), resulting in an increase in Annexin V-FITC+/PI+ cell population from $56 \%( \pm 0.72)$ to $73 \%( \pm 0.21)$ at $48 \mathrm{~h}$ and $72 \mathrm{~h}$, respectively. At even lower CUR (ten times lower than the $\left.\mathrm{IC}_{50}\right)$ and $\mathrm{DOX}\left(\mathrm{IC}_{50}\right)$ concentrations the apoptotic cellular response upon treatment with the 
$(1 \mu \mathrm{M}$ CUR $+0.164 \mu \mathrm{M}$ DOX) peptide hydrogel formulation was considerably higher, compared to the respective of the solution formulation of higher CUR and DOX concentrations after cell exposure for $48 \mathrm{~h}$ and $72 \mathrm{~h}$. It is appreciable that a formulation of lower drug payload can sensitize cells to achieve a reasonable apoptotic efficacy. 


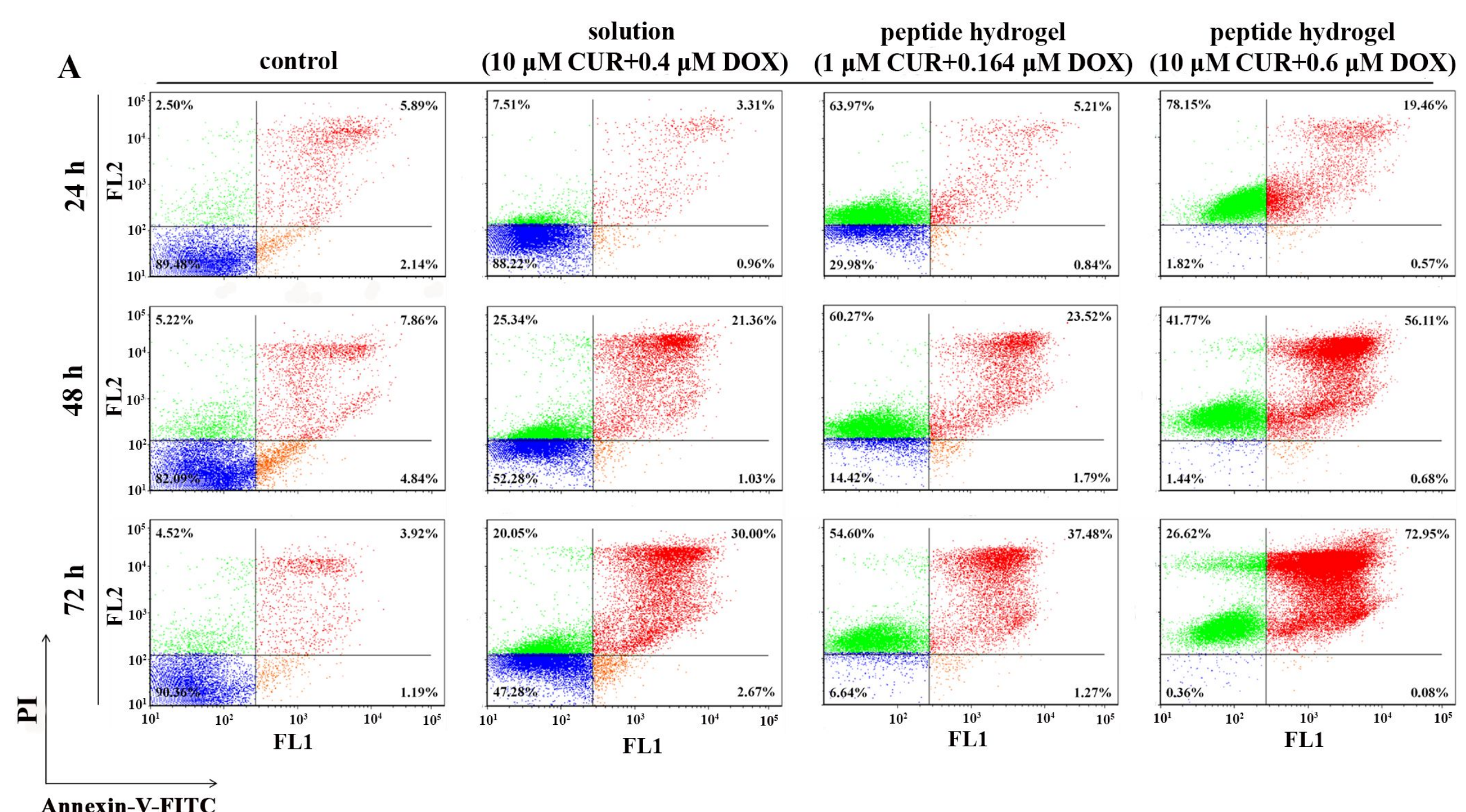




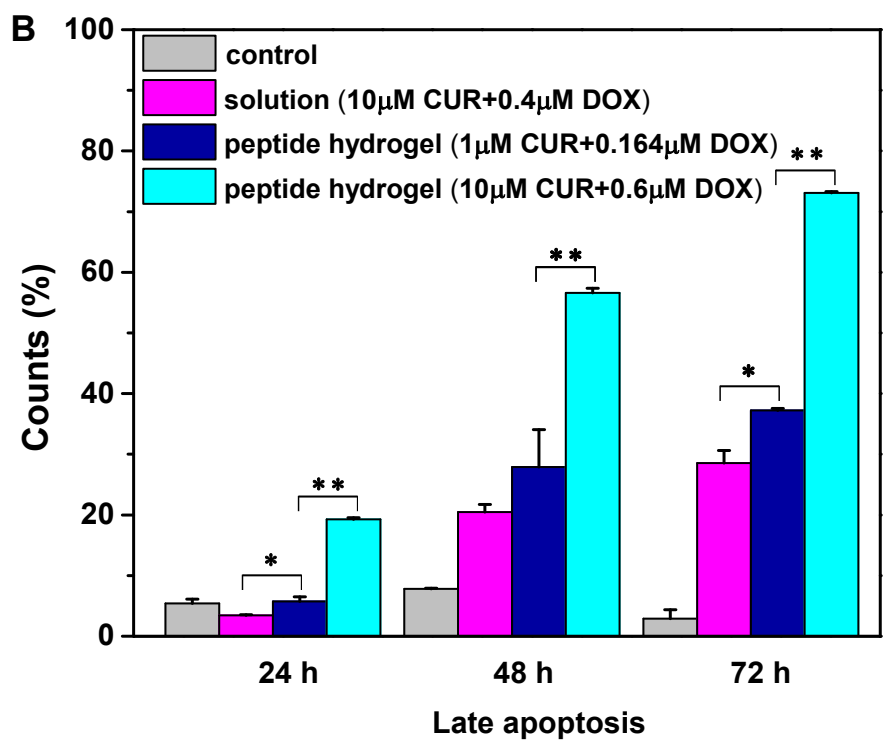

Figure 2. A. Analysis of cell apoptosis by flow cytometry using the Annexin-V-FITC/PI double staining assay in HSC-3 cells. Cells were treated with the drug combination formulations (solution or peptide hydrogel) for $24 \mathrm{~h}, 48 \mathrm{~h}$ and $72 \mathrm{~h}$. Untreated cells were considered as the control. Representative dot plot diagrams are presented, demonstrating viable cells at the lower left quadrant (FITC-/PI-), early apoptotic cells in the lower right quadrant $\left(\mathrm{FITC}^{+} / \mathrm{PI}^{-}\right)$and late apoptotic cells in the upper right quadrant $\left(\mathrm{FITC}^{+} / \mathrm{PI}^{+}\right)$. B. Percentage of late-stage apoptotic HSC-3 cells. Data are presented as the means \pm standard deviation of three independent experiments.

Based on the fact that apoptosis is a process related to DNA damage, ${ }^{68}$ the effect of treatment with the combination formulations on the nuclear phenotype was evaluated using CLSM, after staining cell nuclei with DAPI (Figure S6). Significant variations in the nuclei shape and size could be observed for the treated samples, compared to the respective control samples. ${ }^{69}$ Cells exposed to the $(10 \mu \mathrm{M}$ CUR $+0.4 \mu \mathrm{M}$ DOX $)$ solution and $(10 \mu \mathrm{M}$ CUR $+0.6 \mu \mathrm{M}$ DOX $)$ peptide hydrogel formulations demonstrated the highest degree of nucleus irregularity (asterisk) clearly appearing lobed instead of round at all time-points of treatment, as well as an 
abnormal nucleus enlargement. Another late-apoptotic feature was abnormal chromatin condensation (arrow) mainly observed after $48 \mathrm{~h}$ of treatment. These morphological alterations were also identified in the cells treated with the $(1 \mu \mathrm{M}$ CUR $+0.164 \mu \mathrm{M}$ DOX $)$ peptide hydrogel formulation but to a lesser extent, compared to the ones of higher drug content. The effect of DOX treatment on intranuclear morphology has been previously well documented..$^{70}$ The effect of the combination formulations on the cell cycle progression was evaluated timedependently by analyzing the DNA content of the treated cells using flow cytometry (Figure 3A). A representative cell cycle profile for rapidly proliferating cells was obtained for the untreated HSC-3 cells growing in culture with an average population of $70 \%$ of the cells distributed in the G0/G1 phase, $16 \%$ of the cells in the S phase and $14 \%$ of the cells in the $\mathrm{G} 2 / \mathrm{M}$ phase at the first $12 \mathrm{~h}$, accompanied by the transition from $\mathrm{G} 0 / \mathrm{G} 1$ to $\mathrm{S}$ and $\mathrm{G} 2 / \mathrm{M}$ phases, as indicated by the decrease in the percentage of the G0/G1 phase fraction (40\%) and the corresponding increase in the percentage of the S (20\%) and G2/M (35\%) phase fractions at 24 h. Distinctive cell cycle profiles were obtained for the HSC-3 cells upon treatment with the combination drug concentrations. Cell exposure to the (10 $\mu \mathrm{M}$ CUR $+0.6 \mu \mathrm{M}$ DOX) peptide hydrogel formulation for $24 \mathrm{~h}$ generated a significant accumulation of $65 \%$ of the cell population in the S phase, compared to the respective $20 \%$ of the untreated cells, inducing an S-phase cell cycle arrest. On the other hand, $(1 \mu \mathrm{M}$ CUR $+0.164 \mu \mathrm{M}$ DOX $)$ peptide hydrogel treated cells induced G2/M cell cycle arrest at $24 \mathrm{~h}$ of treatment, with $57 \%$ of the total cell population detected in the $\mathrm{G} 2 / \mathrm{M}$ phase, compared to the $36 \%$ of the control. In both cases, a concomitant reduction in the proportion of cells appertaining to the G0/G1 phase was observed, from control $(43 \%)$ to $(10 \mu \mathrm{M}$ CUR $+0.6 \mu \mathrm{M}$ DOX) peptide hydrogel treatment $(17 \%)$ and $(1 \mu \mathrm{M}$ CUR $+0.164 \mu \mathrm{M}$ DOX) peptide hydrogel treatment $(8 \%)$. An almost equal distribution of the cell population in both the S (43\%) and G2/M (47\%) phases of the cell cycle was observed after cell treatment with the $(10 \mu \mathrm{M}$ CUR $+0.4 \mu \mathrm{M}$ DOX) solution, indicating an 
arrest in the $\mathrm{S}$ and $\mathrm{G} 2 / \mathrm{M}$ phases of the cell cycle. DOX has been previously evaluated in different cell lines and was found to induce a dose-dependent transition of cells in the different phases of the cell cycle, where low DOX concentrations provoke G2/M cycle arrest, whereas high DOX concentrations induce an S-phase block, ${ }^{71,72}$ similar to the results obtained in the present study. The percentage of cells distributed in the phases of cell cycle after each treatment are presented in Figure 3B. 


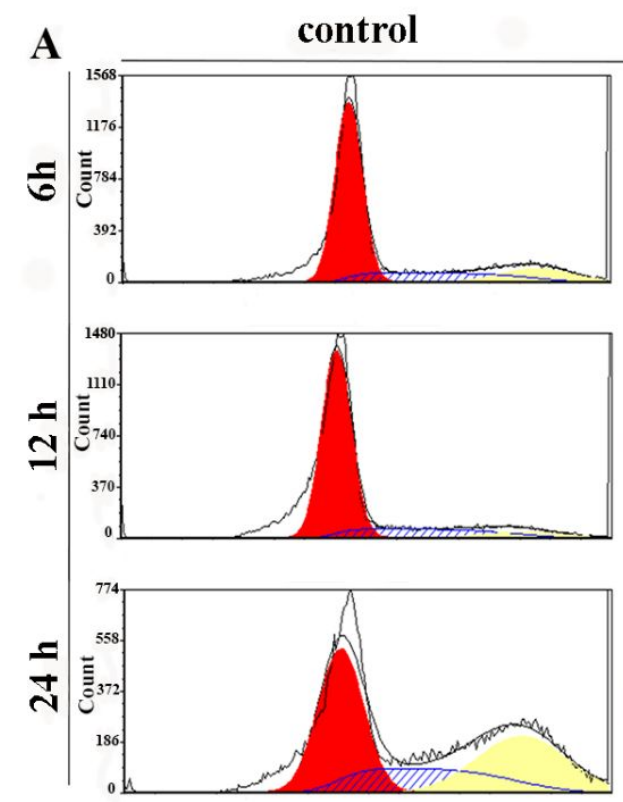

FL2 solution (10 $\mu$ M CUR+0.4 $\mu$ M DOX)
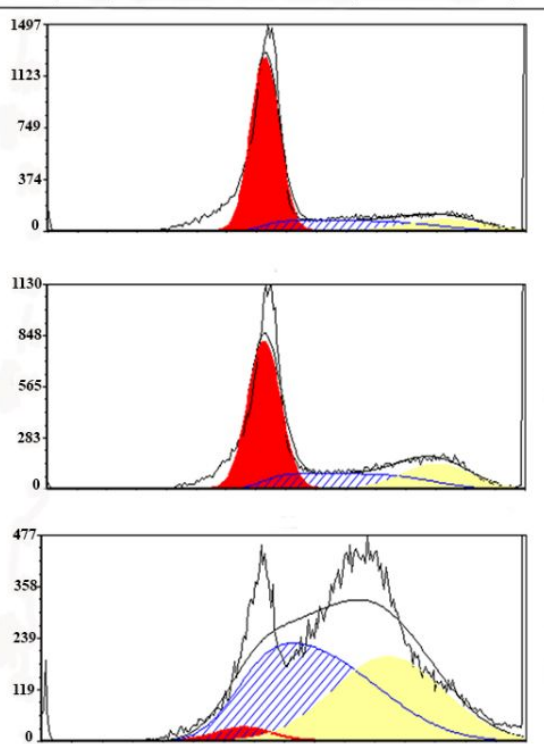

FL2 peptide hydrogel
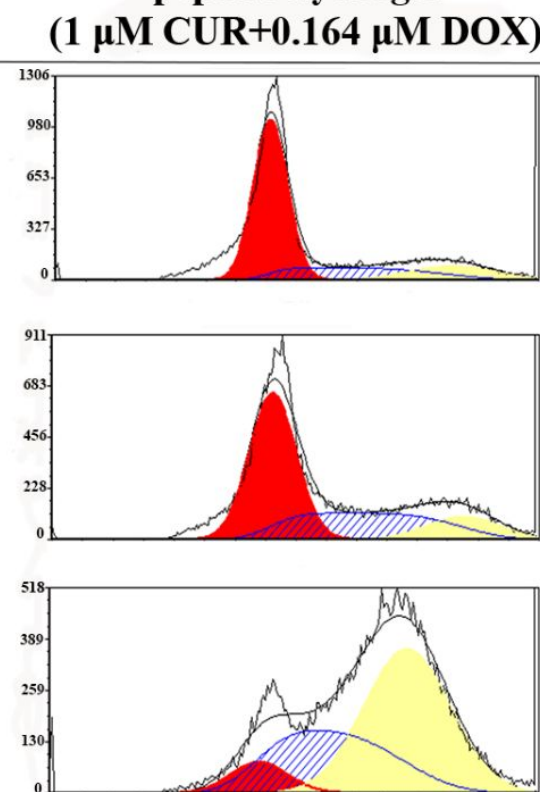

FL2 peptide hydrogel (1 $\mu$ M CUR+0.6 $\mu$ M DOX)
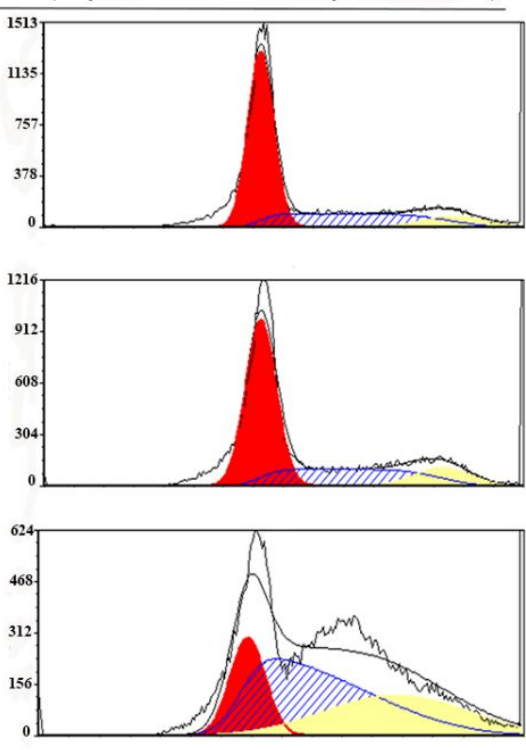

FL2 

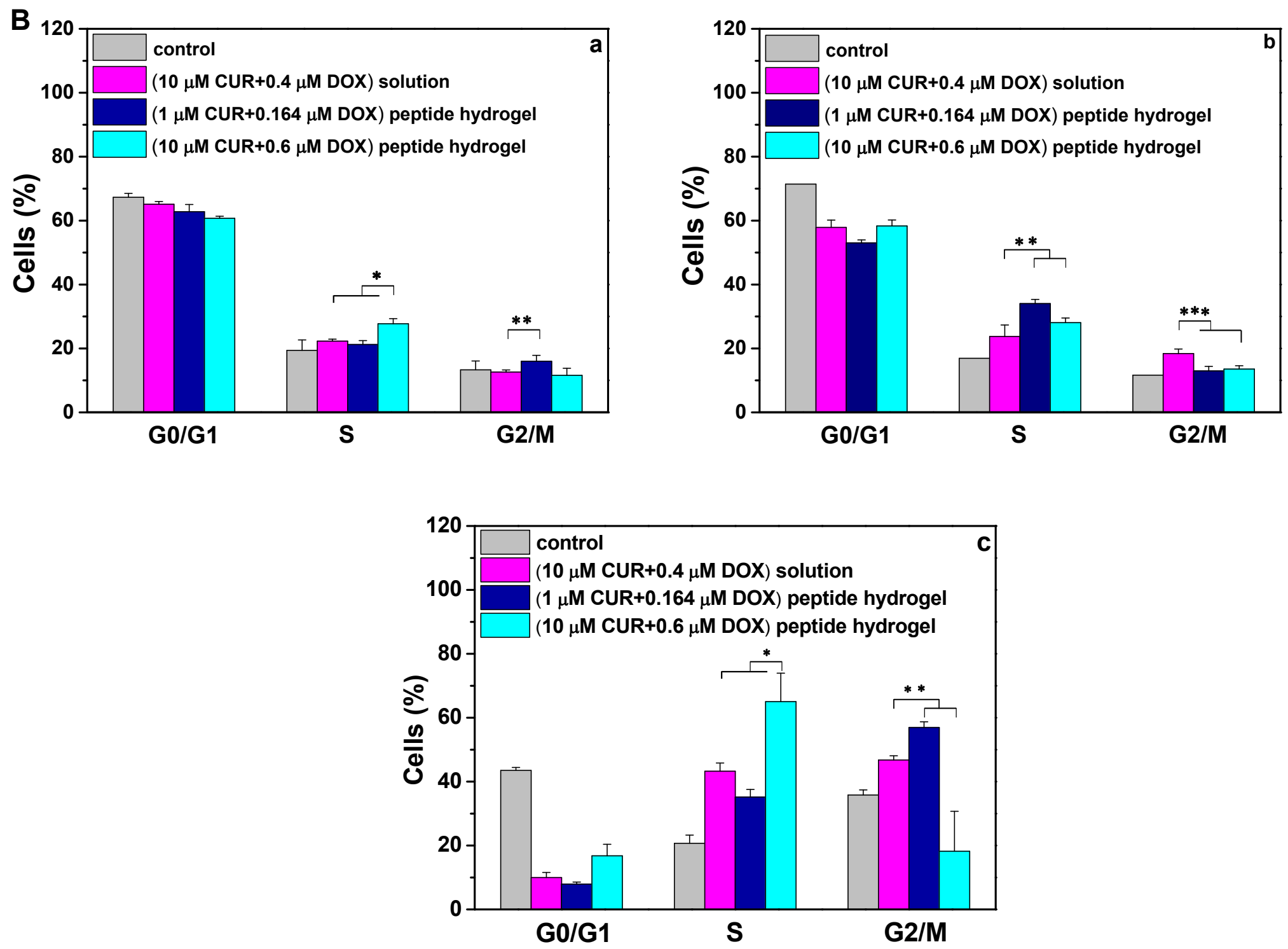
Figure 3. A. Cell cycle analysis of HSC-3 cells after treatment with the drug combination formulations (solution or peptide hydrogel) for $6 \mathrm{~h}, 12 \mathrm{~h}$ and $24 \mathrm{~h}$. Untreated cells were considered as the control. B. Cell distribution (\%) in the phases of cell cycle after treatment for a. $6 \mathrm{~h}$, b. $12 \mathrm{~h}$ and c. $24 \mathrm{~h}$. Results are presented as the means \pm standard deviation of three independent experiments.

Effect of combination formulations on gene expression. Since all selected formulations were found to induce reasonable cytotoxicity and reduced proliferation, the expression patterns of several anti-apoptotic and apoptotic-related genes were analyzed after cell treatment with the combination formulations for $24 \mathrm{~h}$ as shown in Figure S7. A significant up-regulation in the expression of p53 and p21 was found to be induced by all formulations evaluated, compared to the control, with the increase in the levels of gene expression being more pronounced for the $(10 \mu \mathrm{M}$ CUR $+0.6 \mu \mathrm{M}$ DOX) peptide hydrogel treated group. Results also demonstrated a considerable augmentation in the expression of BAX for all treatments and a moderate increase in the levels of BAD (apoptosis-related genes). No appreciable alteration in the expression profile of caspase- 9 was induced by any of the formulations, while only $(10 \mu \mathrm{M}$ CUR +0.6 $\mu \mathrm{M}$ DOX) peptide hydrogel resulted in a significant up-regulation of caspase-3. Caspase-3 has been identified as critical mediator during programmed cell death, ${ }^{73}$ therefore the high rate of late-apoptosis observed for the $(10 \mu \mathrm{M}$ CUR $+0.6 \mu \mathrm{M}$ DOX $)$ peptide hydrogel treatment group is well correlated to the respective over-expression of caspase 3.

No statistically significant changes in the expression of the cell cycle progression regulators Cdk4 and Cdk6 were observed for any of the treatment groups, compared to the control. Considerable up-regulation of Cdk2 and Bcl-2 in response to the (10 $\mu \mathrm{M}$ CUR $+0.6 \mu \mathrm{M}$ DOX $)$ peptide hydrogel treatment was observed. Increased levels of c-myc and CyclD1 expression were observed after cell exposure to the $(10 \mu \mathrm{M}$ CUR $+0.4 \mu \mathrm{M}$ DOX) solution, while the 
hydrogel formulations only slightly induced the expression of the two genes. The latter gene expression changes in Cdk2, Bcl-2, c-myc, and CyclD1 could be considered as an unsuccessful attempt of cells to overcome the higher increase in the expression of apoptotic-related genes that caused the growth inhibitory effect observed in cultures.

In vivo antitumour efficacy. The antitumour efficacy of the selected DOX + CUR peptide hydrogel formulation $(1 \mu \mathrm{M}$ CUR $+0.164 \mu \mathrm{M}$ DOX) was evaluated in HSC-3 cell-xenografted SCID mice (Figure 4). When tumour volume reached approximately $120 \mathrm{~mm}^{3}$, mice were intratumourally administered with saline (control), plain peptide hydrogel (blank), DOX+CUR solution $(1 \mu \mathrm{M}$ CUR+0.164 $\mu \mathrm{M}$ DOX $)$ and DOX+CUR peptide hydrogel $(1 \mu \mathrm{M}$ CUR +0.164 $\mu \mathrm{M}$ DOX) to a total DOX dose of $20 \mathrm{mg} / \mathrm{kg}$ (four administrations). Tumour volume (Figure 4A) and body weight (Figure 4B) were regularly monitored till the end of the study period on day 15.

As shown in Figure 4A, all treatment groups demonstrated similar tumour growth profiles until day 6. The highest antitumour efficacy was evidenced in the group treated with the DOX + CUR peptide hydrogel (one-way Anova: $\mathrm{F}=40.25, \mathrm{p}<0.001$ ), which showed the most significant reduction in tumour volume of approximately $-21 \%$ of the initial tumour size at the end of the study on day $15\left(112.54 \pm 102.57 \mathrm{~mm}^{3}\right)$, compared to the control $(\mathrm{p}<0.01)$, blank $(\mathrm{p}<0.01)$ and drug solution $(p<0.05)$ treatment groups as revealed by Tukey's post hoc test. The administration of the DOX + CUR solution induced a significant tumour inhibitory effect after day 6 , which effect however was not retained, since after day 9 tumour started to grow and reached to $368 \%$ of the initial volume at the end point of the study $\left(490.25 \pm 70.09 \mathrm{~mm}^{3}\right)$. As expected, both the control and the blank treated groups showed the highest tumour proliferation. Notably, the group administered with the plain peptide hydrogel reported a significantly higher tumour growth behavior that reached to $626 \%$ of the initial tumour size 
$\left(959.49 \pm 10.14 \mathrm{~mm}^{3}\right)$, compared to the respective $377 \%$ of the saline treated group $(645.32 \pm$ $\left.90.04 \mathrm{~mm}^{3}\right)$ at the end of the study. The ac-(RADA $)_{4}-\mathrm{CONH}_{2}$ peptide hydrogel has been extensively utilized as a synthetic matrix to promote cell growth and differentiation, with numerous applications in in vitro $3 \mathrm{D}$ cell culture and tissue regeneration, ${ }^{13,74}$ justifying the favorable tumour growth profile observed in the present study for the blank group.

The body weight of the HSC-3 cell-xenografted SCID mice was monitored throughout the study period as a toxicity parameter of the administered treatments. As shown in Figure 4B, no significant body weight changes were observed for the saline, plain peptide hydrogel and DOX+CUR peptide hydrogel treatment groups until the end of the study. On the contrary, the xenografted SCID mice administered with the DOX+CUR solution demonstrated a considerable body weight loss after day 6 from treatment initiation, that became more prominent at the end of the study period, thus indicating the toxicity of the administered treatment $(\mathrm{p}<0.05)$.

The mean tumour weight of each treatment group was determined after excision from the mice at the end point of the study (Figure 4C). A significantly higher tumour weight reduction was induced in the DOX+CUR peptide hydrogel treatment group (one-way Anova: $\mathrm{F}=8.41$, $\mathrm{p}<0.05$ ), with the tumour weight differences among the treatment groups following the order DOX + CUR peptide hydrogel $<$ DOX + CUR solution $<$ saline $<$ peptide hydrogel, as also illustrated in Figure 4D.

Overall, the results of the in vivo study designated the superiority of the DOX + CUR peptide hydrogel formulation ( $1 \mu \mathrm{M}$ CUR+0.164 $\mu \mathrm{M}$ DOX) to efficiently suppress tumour growth. 

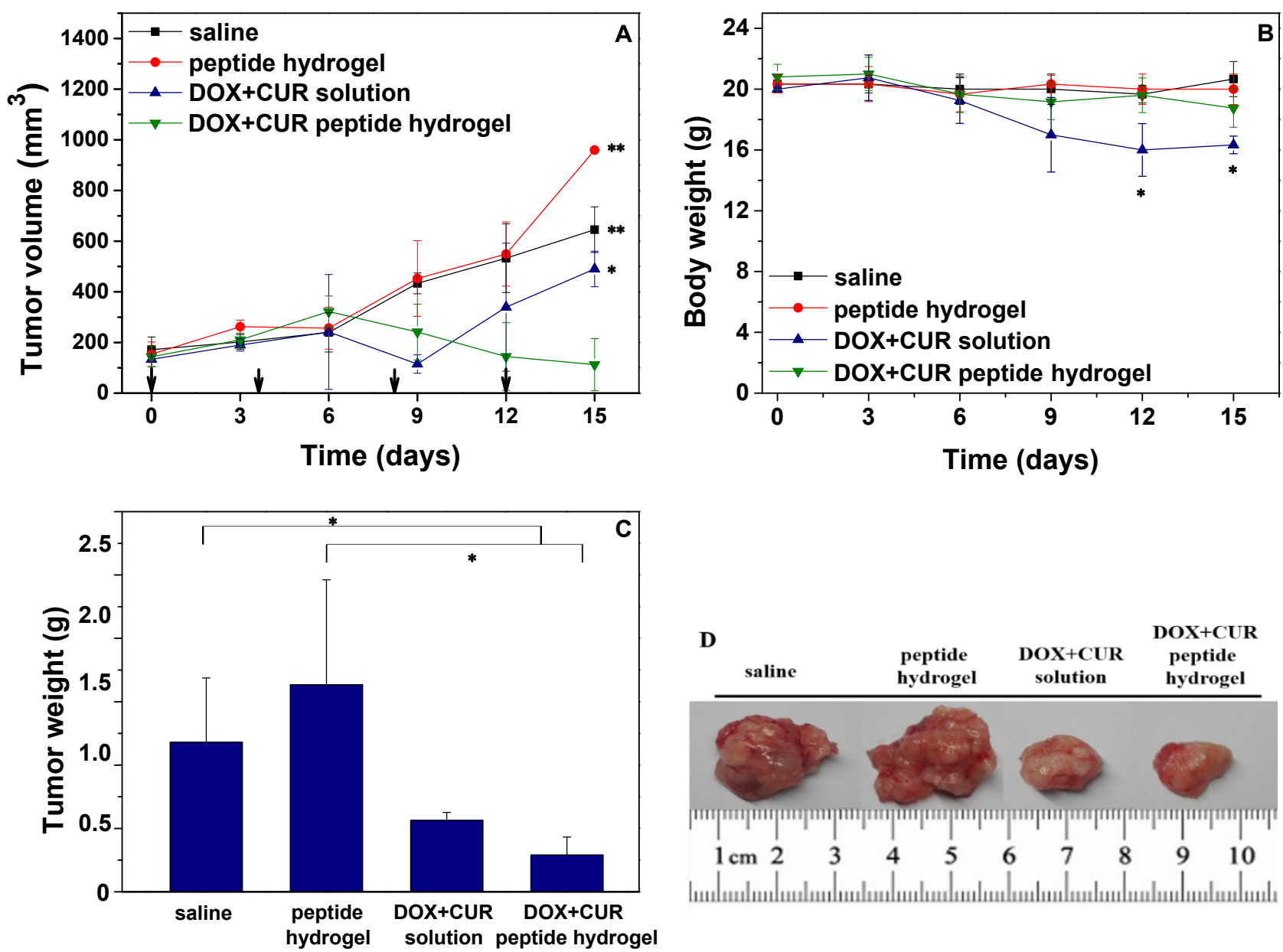

Figure 4. In vivo antitumour efficacy of DOX+CUR loaded peptide hydrogel $(1 \mu \mathrm{M}$ CUR $+0.164 \mu \mathrm{M}$ DOX) in HSC-3 cell-xenografted SCID mice after intratumoural administration. A. Tumour volume $\left(\mathrm{mm}^{3}\right)$ (arrows indicate intratumoural administration of each treatment, $* \mathrm{P}<0.05$ vs DOX $+\mathrm{CUR}$ solution and ${ }^{* *} \mathrm{p}<0.01$ vs control and blank treatment groups, as revealed by Tukey post hock test). and B. body weight (g) change were recorded every three days following treatment with saline, the peptide hydrogel, DOX + CUR solution $(1 \mu \mathrm{M}$ CUR+0.164 $\mu \mathrm{M}$ DOX) and DOX+CUR peptide hydrogel ( $1 \mu \mathrm{M}$ CUR+0.164 $\mu \mathrm{M}$ DOX). C. Tumour weight ( $* \mathrm{P}<0.05$ vs control and blank treatment groups) and D. representative images of tumours excised at the end point of the study on day 15. Data are presented as mean values \pm S.D. $(n=4)$. 
Organ-to-body weight ratios. Organ weight analysis was performed at the end of the study as an indicator of potential toxic effects induced by the administered treatments. ${ }^{75}$ Results were expressed as organ weight $(\mathrm{mg})$ to body weight $(\mathrm{g})$ ratios. As shown in Figure S8, no statistically significant differences were observed in the organ-to-body weight ratios of all major organs (liver, spleen, kidney, heart) in the majority of the treatment groups. The only exception was observed in the DOX+CUR solution treated group for which the liver-to-body weight ratio was significantly higher compared to the control (saline group). This observation might be an indication of liver toxicity, because of potential systemic drug exposure after the administration of the DOX+CUR solution.

Histological examination. H\&E-stained tumour and major organ (liver, kidney, spleen, heart) sections of all treatment groups are shown in Figure 5. Histological examination revealed no specific toxicity or tissue damage in the examined organs of the different treatment groups, compared to the control. All tumour specimens consisted of well-differentiated squamous cell carcinoma similar to the injected HSC-3 cells with varying size and type of peripheral expansion-invasion. Each group of tumour cells consists of a peripheral layer of small basophilic cells and much larger eosinophilic cells centrally. These are forming masses of keratin in some foci called keratinous pearls, as indicated by the arrows in the tumour sections of the saline and plain peptide hydrogel groups. Individual cell keratinization is also evident in the tumour sections of the plain peptide hydrogel, the DOX + CUR solution and DOX + CUR peptide hydrogel treated groups (thick arrows). The nuclei of the tumour cells show pleomorphism, prominent nucleoli and moderate mitotic and apoptotic rate, while the stroma between the groups of tumour cells is infiltrated with small lymphocytes.

Significant tumour shrinkage was observed in the case of the DOX + CUR peptide hydrogel treated group with characteristics of local necrosis and degeneration, as well as the retention of 
varying peripheral invasion. A more moderate tumour shrinkage and necrosis was evidenced in the DOX+CUR solution treatment group, while peripheral invasion was found to be more pronounced. Tumour sections of the peptide hydrogel treated group demonstrated a significant increase in tumour size and important disposition for peripheral expansion without characteristics of tumour necrosis. 


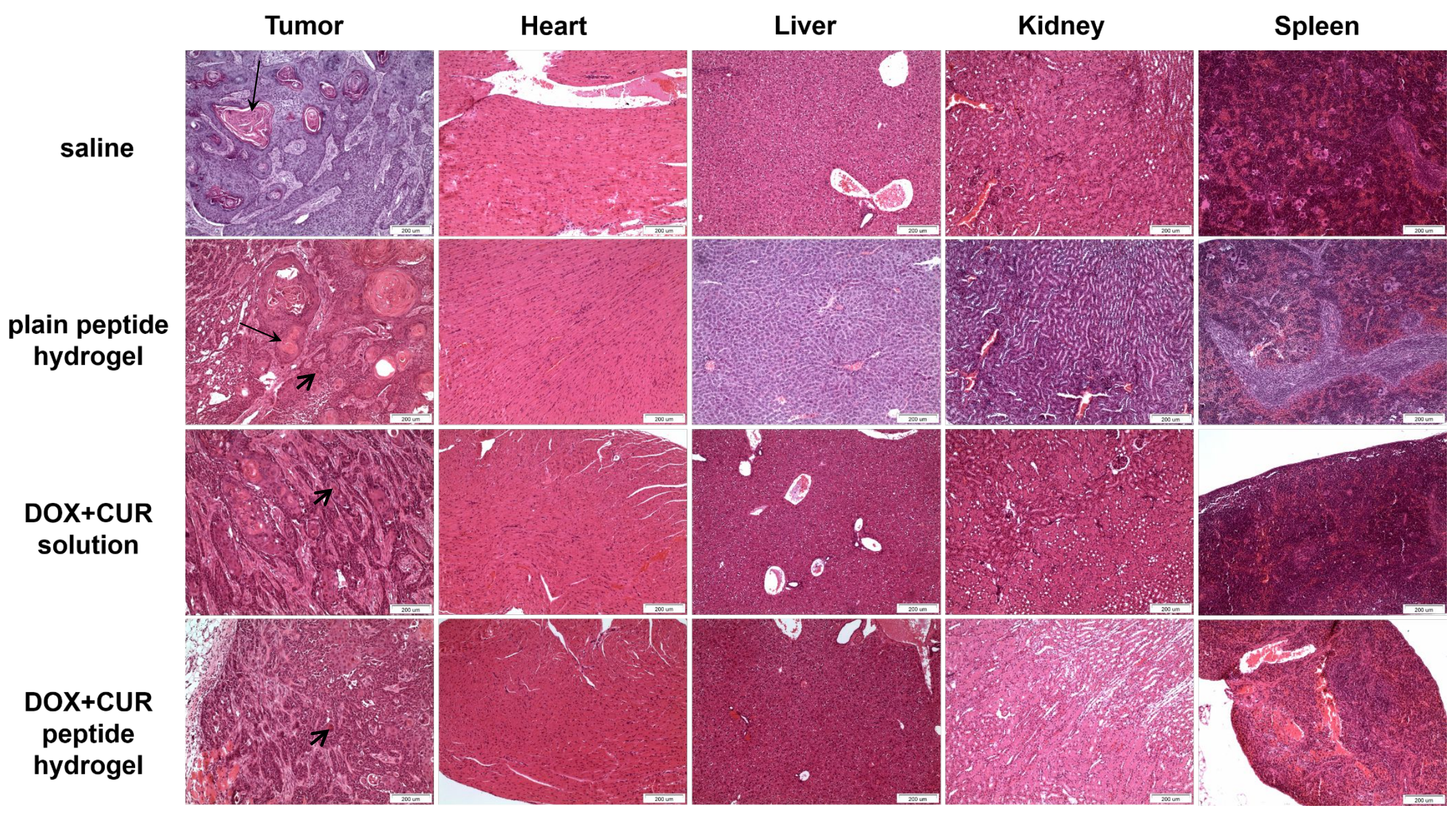


Figure 5. Histological sections of the tumours and major organs (heart, liver, kidney, spleen) of HSC-3 cell-xenografted SCID mice at the end of the study on day 15. Mice were intratumourally administered with saline, plain peptide hydrogel, DOX + CUR solution $(1 \mu \mathrm{M}$ CUR $+0.164 \mu \mathrm{M}$ DOX) and DOX+CUR peptide hydrogel $(1 \mu \mathrm{M}$ CUR+0.164 $\mu \mathrm{M}$ DOX). Tissue sections were stained with haematoxylin and eosin (magnification: x10). Thin arrows indicate forming masses of keratin called keratinous pearls. Thick arrows are indicative of individual cell keratinization.

3D histological examination by means of $\boldsymbol{\mu C T}$. Micro-CT imaging of the tumour biopsies provided a unique insight in the 3D morphological characteristics of the excised tumours allowing us to quantitively analyze the volume and spatial distribution of the three main anatomical features of interest; namely the whole tumour, the necrotic tissue contained in each tumour, and the calcifications associated with the necrotic tissue. The results of the analysis are summarized in Figure S9.

In line with the results of the gross anatomical examination of the tumours' weight (Figure 9), the total volume of the excised tumours followed the same order; that is DOX+CUR peptide hydrogel $\left(105.13 \mathrm{~mm}^{3}\right)<$ DOX+CUR solution $\left(156.94 \mathrm{~mm}^{3}\right)<$ saline $\left(195.85 \mathrm{~mm}^{3}\right)<$ peptide hydrogel $\left(256.21 \mathrm{~mm}^{3}\right)$. A side-by-side comparison is presented in Figure 6. 


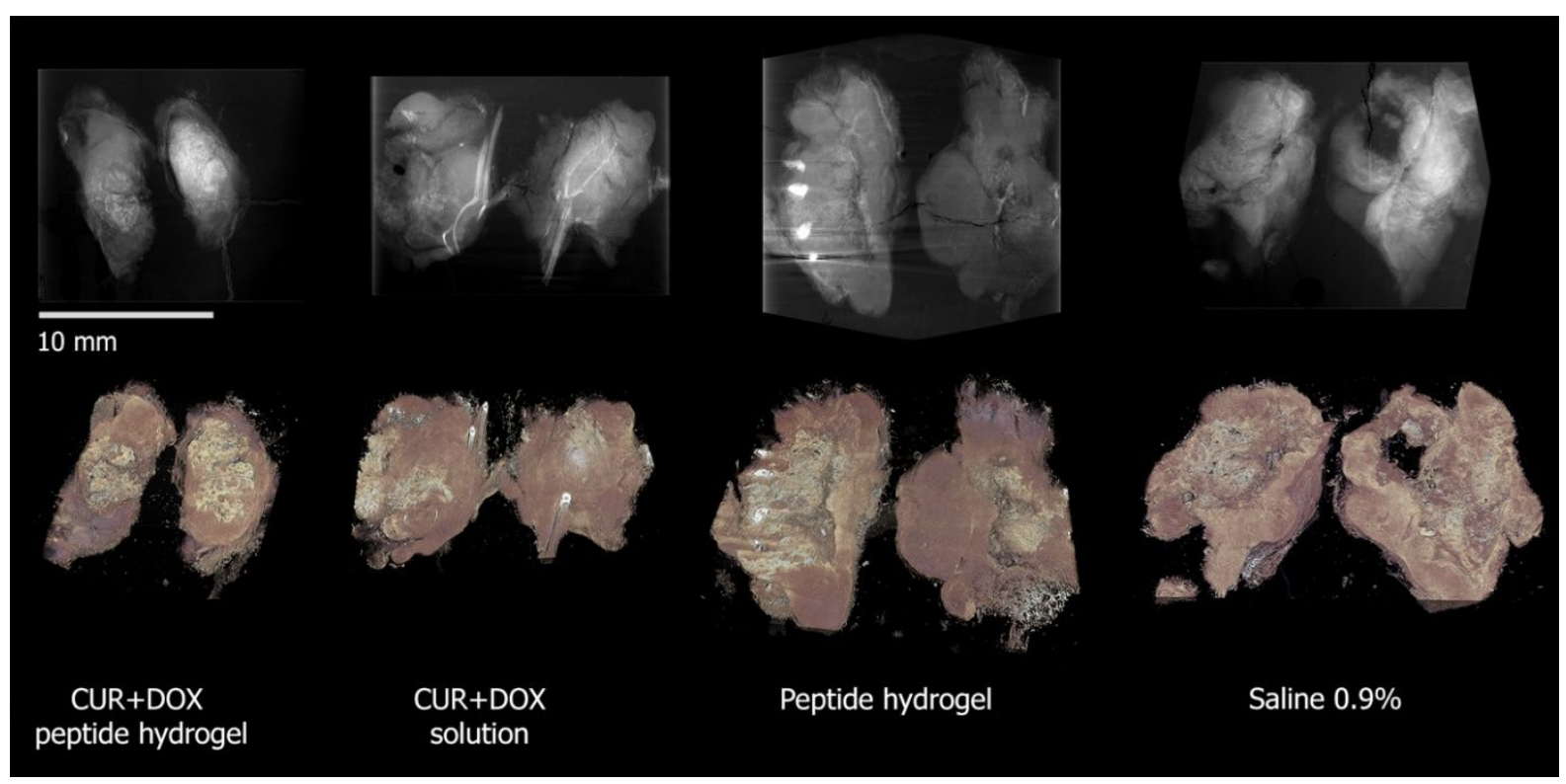

Figure 6. Side-by-side comparison of the tumours studied by $\mu \mathrm{CT}$; Top row: Summation of intensity along the stack of CT slices (n slices $\sim=400$ ) showing density variations and overall dimensions of the tumours; Bottom row: 3D photorealistic rendering of the tumours (also see supplementary videos 1-4).

$\mu \mathrm{CT}$ also allowed us to quantify the extent of the necrotic tissue within each tumour. These areas are located in the core of the tumour, consist of dead cells, extracellular matrix and often contain calcifications and are the result of tumour's rapid growth and subsequent nutrient starvation. ${ }^{76}$ Necrotic areas appear brighter in $\mu \mathrm{CT}$ and they were identified by experienced histopathologist. As expected, the fastest growing tumours, i.e. the ones treated with saline and peptide hydrogel, had significantly larger necrotic cores compared to the drug-treated tumours. Specifically, the peptide hydrogel- and the saline- treated tumours had necrotic tissue volumes of $29.83 \mathrm{~mm}^{3}$ and $13.16 \mathrm{~mm}^{3}$, while the corresponding necrotic core sizes for the drug-treated tumours were 5.29 $\mathrm{mm}^{3}$ and $4.05 \mathrm{~mm}^{3}$ for the DOX + CUR peptide hydrogel and the DOX + CUR solution, respectively. 
Interestingly, investigation of the ratio between the total tumour volume and the necrotic volume within them showed that $2.58 \%$ of the total tumour volume in the DOX+CUR solution-treated tumour was necrotic, while the corresponding percentage in the DOX + CUR peptide hydrogel was $5.29 \%$; accounting for a $94.75 \%$ increase in necrotic core size for the latter (Figure 7). Given the comparable total volume sizes between the two treatment groups, these results indicate that the DOX+CUR peptide hydrogel-treated tumour shows a lower proliferation activity compared to the its DOX+CUR solution-treated counterpart, with the majority of the total tumour volume occupied by a necrotic core area. It is known that extract of necrotic tumours can reduce the growth of proliferating cells, ${ }^{77}$ further supporting the findings of the microstructural examination of the drug treated tumour groups in the present study, while at the same time highlighting the efficacy of the DOX+CUR peptide hydrogel to enhance tumour necrosis and suppress tumour cell proliferation. Videos illustrating $2 \mathrm{D}$ and $3 \mathrm{D}$ renderings of the $\mu \mathrm{CT}$ volume data of the respective excised tumours are presented at Supplementary Information.

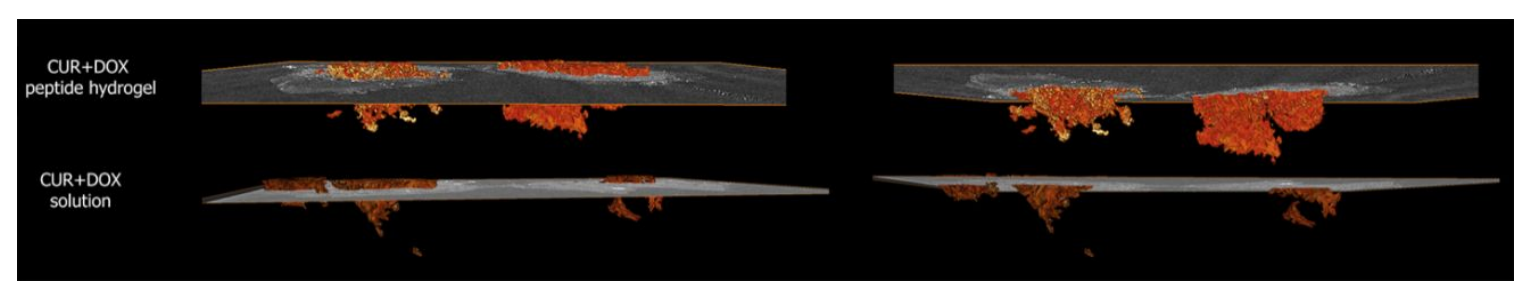

Figure 7. 3D rendering of the segmented necrotic core of the two drug-treated tumours shown against a single $\mu \mathrm{CT}$ slice (left: top view and right: bottom view). For comparable total tumour volumes between the DOX+CUR peptide hydrogel-treated and the DOX+CUR solution-treated tumours, the necrotic core volume was increased by $94.75 \%$ in the case of DOX + CUR peptide hydrogel treatment. 
Finally, our results showed that the presence of calcifications, as confirmed by Alizarin Red (Figure 8), in the necrotic core differed significantly between the peptide hydrogel-treated tumour (total calcifications area $=0.77 \mathrm{~mm}^{3}$ ) and the rest of the treatments, where total calcification area for saline was $0.20 \mathrm{~mm}^{3}$, for DOX+CUR solution was $0.33 \mathrm{~mm}^{3}$ and for DOX+CUR peptide hydrogel was $0.48 \mathrm{~mm}^{3}$ (Figure S9). Calcium deposition occurs during cell necrosis resulting in the formation of a necrotic core that is surrounded by less-degraded and less-calcified material. ${ }^{76}$ A structural stratification of the tumours is evident that is characterized by an increasingly calcified tumour core with distance from the tumour leading edge, resulting from the viable rim cell flux towards the necrotic core. ${ }^{78} \mathrm{~A}$ linear correlation between calcification size and tumour size has been previously reported based on clinical data. ${ }^{78}$ Our study did not confirm this linear relationship between total tumour volume and amount of calcifications although the bigger tumour had indeed the highest amount of deposits. However, comparing the total volume of calcifications with the total volume of the necrotic core revealed an interesting relationship. Both DOX + CUR treated tumours had much higher percentage of calcification in their necrotic cores, compared to the nondrug treated tumours, possibly attributed to the enhanced tumour cell death induced following drug treatment.

As a matter of fact, the two agents, curcumin and doxorubicin, share common molecular effects on inducing apoptosis-related target genes and obviously their co-administration, as shown in this study is beneficial for enhanced apoptotic anticancer activity. The assessment of the expression level of apoptosis- and cell cycle-related presented in this work has shown that a significant upregulation of p53 and p21 happened upon the exposure of $\mathrm{HSC}-3$ cells for $24 \mathrm{~h}$ with the peptideloaded curcumin and doxorubicin formulation, implying a cell-cycle arrest. Moreover, such cell cultures indicated also activation of Bax, Bad and caspase-3 genes, suggesting the activation of 
the apoptotic machinery too. This gene expression profile exhibited a concentration-dependent manner (Figure S7). Importantly, the synergistic apoptotic effect of the peptide-loaded curcumin and doxorubicin formulation in the analyzed by $\mu$-CT animal tumour samples further confirmed such conclusion, through the identification of extended apoptotic foci and calcification core.

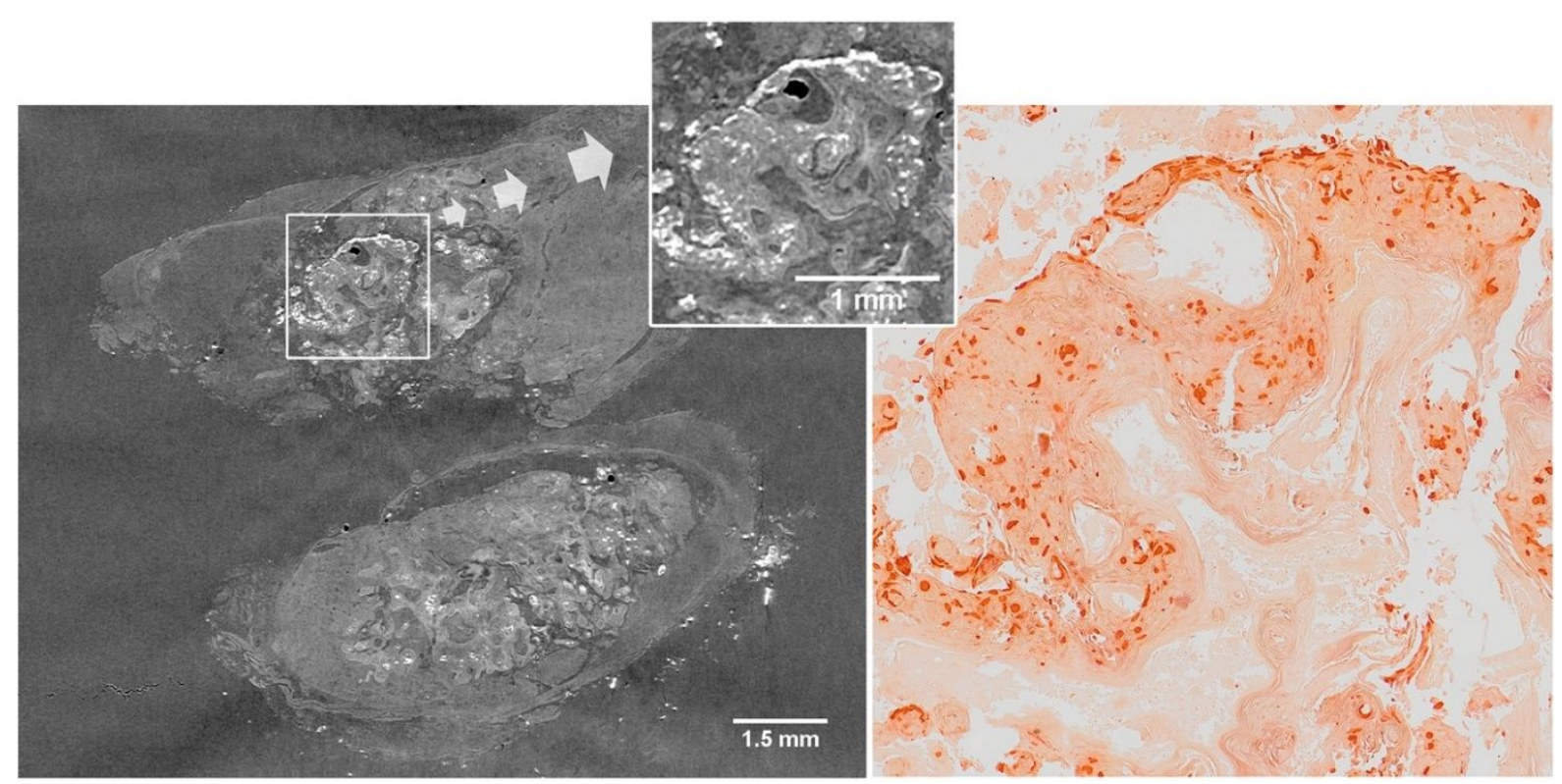

Figure 8. Co-registered $\mu \mathrm{CT}$ and histological section stained with Alizarin Red showing the presence of calcifications (dark red spots in histology and bright spots in $\mu \mathrm{CT}$ ) in the necrotic core of a biopsy. The histological section imaged using a Dot-Slide scanning system. To achieve good visual agreement the initial histology image required deformation, rotation and translation which was performed in imageJ using BigWarp. ${ }^{79}$

In vivo assessment of apoptosis by TUNEL assay. Analysis of apoptosis in tumour and heart tissue sections was evaluated using the TUNEL assay (Figure 9A and 9B). No signs of tumour cell apoptosis were observed in both the saline and the peptide hydrogel treated groups and the cell nuclei were evidenced to undergo karyokinesis, demonstrating vigorous proliferation and a tight 
arrangement. A moderate degree of cell apoptosis was observed in the DOX+CUR solution treatment group, while TUNEL-positive cells significantly increased under treatment with the DOX+CUR peptide hydrogel, demonstrating DNA condensation (white arrows) and a loose distribution. Heart tissue sections were also examined to assess the potential of doxorubicininduced cardiotoxicity. None of the treatment groups was found to induce any apoptotic effects on myocardial cells.

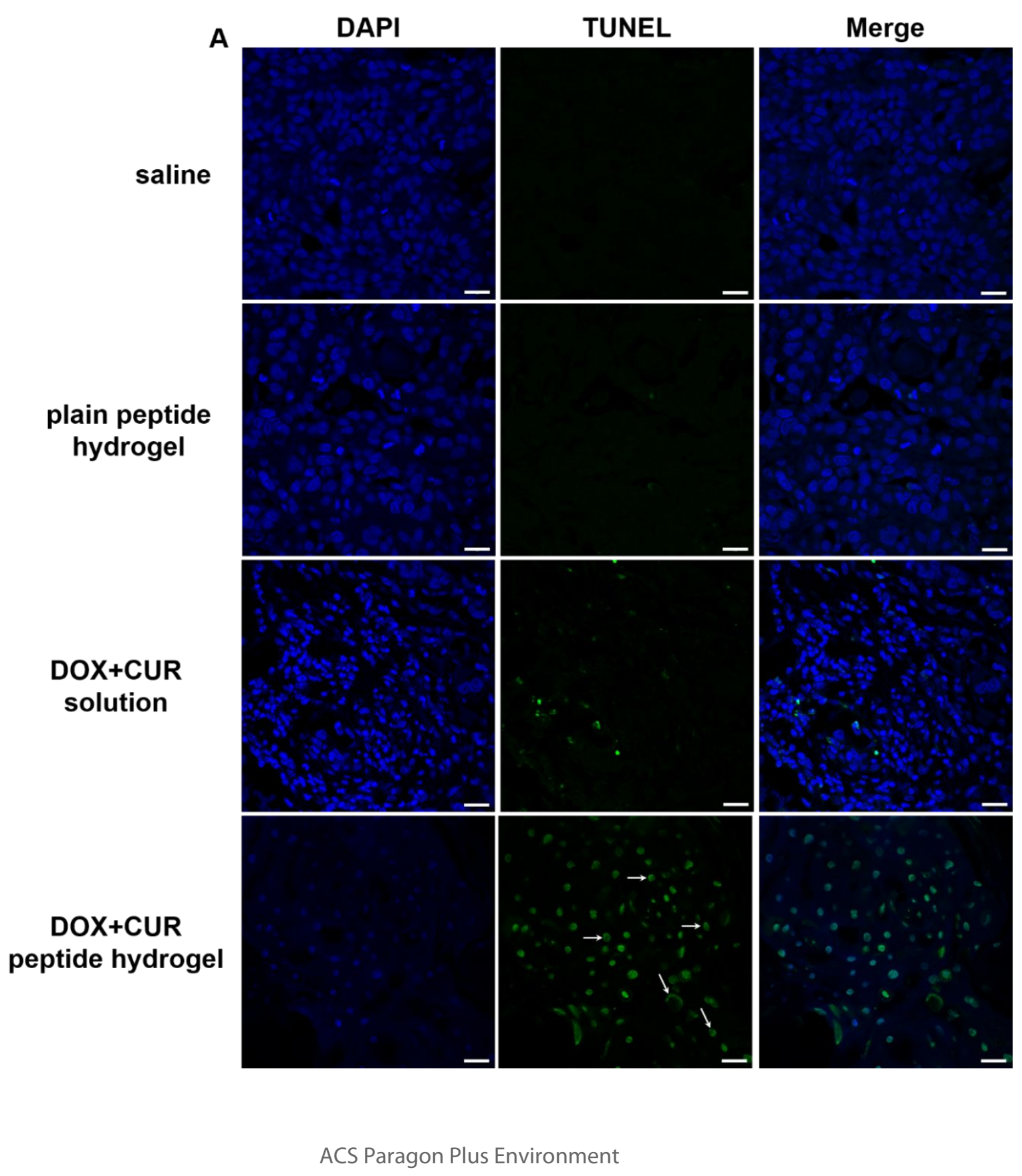




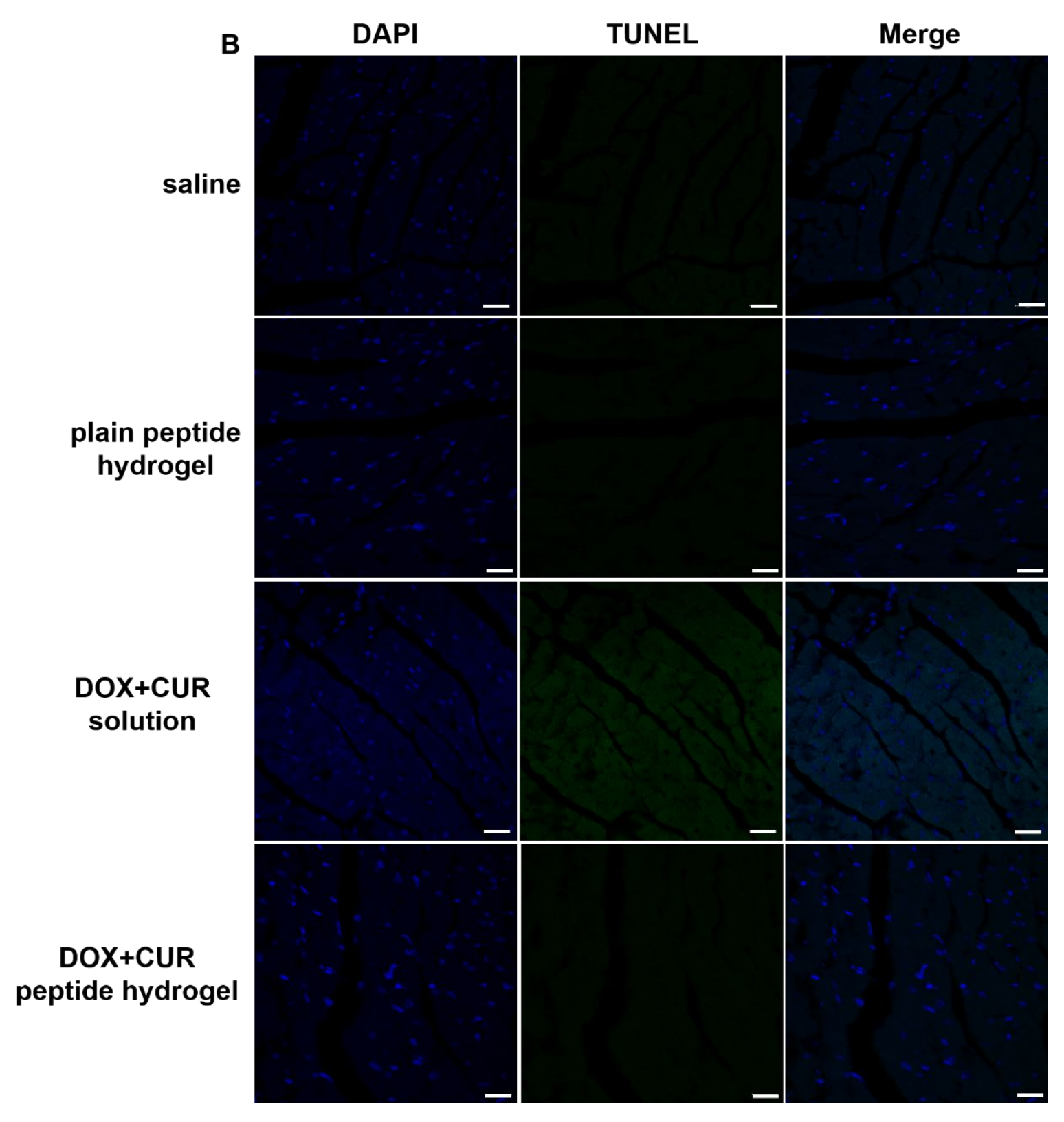

Figure 9. Detection of apoptosis in A. tumour and B. heart tissue sections by TUNEL staining at the end of the treatment period with saline, plain drug hydrogel, DOX + CUR solution $(1 \mu \mathrm{M}$ CUR+0.164 $\mu \mathrm{M}$ DOX) and DOX+CUR peptide hydrogel ( $1 \mu \mathrm{M}$ CUR+0.164 $\mu \mathrm{M}$ DOX). TUNELpositive apoptotic cells are stained green. Cell nuclei are stained with DAPI (blue). Scale bar: 20 $\mu \mathrm{m}$. 
In summary, the stimulus-responsive self-assembling peptide hydrogel ac-(RADA) ${ }_{4}-\mathrm{CONH}_{2}$ has been successfully implemented as a pertinent candidate for the local administration of a drug combination against head and neck cancer. The hydrogel system enabled the simultaneous codelivery of drug moieties with different aqueous solubility and at a different release rate. The dual drug loaded hydrogels significantly enhanced cell growth inhibition, demonstrating considerable synergy even at concentrations well below the IC50 values of both drugs, compared to the respective dual drug solutions. The dual drug loaded hydrogel formulations were found to exert an appreciable in vitro apoptotic response on HSC-3 cells and an appreciable antitumour efficacy against HSC-3 tumour bearing SCID mice. $\mu \mathrm{CT}$ imaging of the tumour biopsies facilitated quantitative analysis of the volume and spatial distribution of the anatomical tumour features. Tumours treated with the dual-loaded peptide hydrogel showed the lowest volume with the majority of the total tumour volume occupied by a necrotic core area. Undisputedly, the embodiment of biocompatible delivery systems in conventional chemotherapeutic approaches constitutes a compelling force in the advancement of localized chemotherapy.

\section{AUTHOR INFORMATION}

Corresponding Author

*Dimitrios G. Fatouros, e-mail: dfatouro@pharm.auth.gr, Tel: +30 2310 997653, Fax: +30 2310 997652

\section{Author Contributions}

The manuscript was written through contributions of all authors. All authors have given approval to the final version of the manuscript. 


\section{Acknowledgments}

C.K. is supported by the Onassis Foundation with a $\mathrm{PhD}$ scholarship. Dr. P. Peristeropoulou (Department of Cytology of St. Andrews General Hospital of Patras, Patras, Greece) is gratefully acknowledged for the histological evaluation of the tumour sections. We also acknowledge $\mu$-VIS X-Ray Imaging Centre at the University of Southampton for provision of tomographic imaging facilities, the Biomedical Imaging Unit at the University of Southampton, and Nikon X-Tek Systems Ltd for the provision of the Med-X prototype scanner. We are particularly grateful to Prof. Suzan Wilson and Jenny Norman (Histochemistry Research Unit, Faculty of Medicine, University of Southampton, UK) for the preparation of Alizarin Red - stained sections, and Matthew Lawson for whole-slide imaging of the Alizarin Red-stained sections. We acknowledge the technical assistance provided by Dr. E. Karoutsos for the AFM measurements (Department of Materials Science, University of Patras, 26504 Rio, Patras, Greece).

Supporting Information. Table S1. Primer sequences used for real-time PCR quantification; Figure S1. AFM images of the ac-(RADA) $)_{4}-\mathrm{CONH}_{2}$ peptide solution; Figure S2. In vitro release profiles in acetate buffer (0.1\% Tween 80) pH 5.0; Figure S3. Biopsy segmentation; Figure S4. Dose-response curves of HSC-3 cell cultures; Figure S5. Inhibitory effect on HSC-3 cell growth; Figure S6. CLSM images of HSC-3 cells after treatment with the drug combination formulations; Figure S7. RT-qPCR analysis of gene expression in HSC-3 cells; Figure S8. Organ-to-body weight ratios (mg/g) of liver, spleen, kidney and heart; Figure S9. Quantification of the tumour biopsy anatomical characteristics; Supplementary Video 1: CUR + DOX peptide hydrogeltreated tumour; Supplementary Video 2: CUR + DOX solution hydrogel; Supplementary Video 3: Peptide hydrogel-treated tumour; Supplementary Video 4: Saline-treated tumour. 


\section{References}

1. Hsu, HW.; Wall, NR.; Hsueh, CT.; Kim, S.; Ferris, RL.; Chen, CS.; Mirshahidi, S. Combination antiangiogenic therapy and radiation in head and neck cancers. Oncol. 2014, 50, 19-26.

2. Kundu, SK.; Nestor, M. Targeted therapy in head and neck cancer. Tumour Biol. 2012, 33, 707721.

3. Dimery, IW.; Hong, WK. Overview of combined modality therapies for head and neck cancer. J. Natl. Cancer Inst. 1993, 85, 95-111.

4. Wilken, R.; Veena, MS.; Wang, MB.; Srivatsan, ES. Curcumin: A review of anti-cancer properties and therapeutic activity in head and neck squamous cell carcinoma. Mol. Cancer. 2011, $10,12$.

5. Anand, P.; Sundaram, C.; Jhurani, S.; Kunnumakkara, AB.; Aggarwal, BB. Curcumin and cancer: an "old-age" disease with an "age-old" solution. Cancer Lett. 2008, 267, 133-164.

6. Zlotogorski, A.; Dayan, A.; Dayan, D.; Chaushu, G.; Salo, T.; Vered, M. Nutraceuticals as new treatment approaches for oral cancer--I: Curcumin. Oral Oncol. 2013, 49, 187-191.

7. Das, T.; Sa, G.; Saha, B.; Das, K. Multifocal signal modulation therapy of cancer: ancient weapon, modern targets. Mol. Cell Biochem. 2010, 336, 85-95.

8. Borges, GÁ.; Rêgo, DF.; Assad, DX.; Coletta, RD.; De Luca Canto, G.; Guerra, EN. In vivo and in vitro effects of curcumin on head and neck carcinoma: a systematic review. J. Oral Pathol. Med. 2017, 46, 3-20.

9. Norouzi, M.; Nazari, B.; Miller, DW. Injectable hydrogel-based drug delivery systems for local cancer therapy. Drug Discov. Today. 2016, 21, 1835-1849. 
10. Wolinsky, JB.; Colson, YL.; Grinstaff, MW. Local drug delivery strategies for cancer treatment: gels, nanoparticles, polymeric films, rods, and wafers. J. Control. Release. 2012, 159, 14-26.

11. Zhang, S. Emerging biological materials through molecular self-assembly. Biotechnol. Adv. 2002, 20, 321-339.

12. Mora-Solano, C.; Wen, Y.; Han, H.; Chen, J.; Chong, AS.; Miller, ML.; Pompano, RR.; Collier, JH. Active immunotherapy for TNF-mediated inflammation using self-assembled peptide nanofibers. Biomaterials. 2017, 149, 1-11.

13. Koutsopoulos, S. Self-assembling peptide nanofiber hydrogels in tissue engineering and regenerative medicine: progress, design guidelines, and applications. J. Biomed. Mater. Res. A 2016, 104, 1002-1016.

14. Koutsopoulos, S.; Unsworth, LD.; Nagai, Y.; Zhang, S. Controlled release of functional proteins through designer self-assembling peptide nanofiber hydrogel scaffold. Proc. Natl. Acad. Sci., USA 2009, 106, 4623-4628.

15. Branco, MC.; Pochan, DJ.; Wagner, NJ.; Schneider, JP. Macromolecular diffusion and release from self-assembled beta-hairpin peptide hydrogels. Biomaterials 2009, 30, 1339-1347.

16. Koutsopoulos, S.; Zhang, S. Long-term three-dimensional neural tissue cultures in functionalized self-assembling peptide hydrogels, Matrigel and Collagen I. Acta Biomater. 2013, 9, 5162-5169.

17. Zou, Z.; Zheng, Q.; Wu, Y.; Guo, X.; Yang, S.; Li, J.; Pan, H. Biocompatibility and bioactivity of designer self-assembling nanofiber scaffold containing FGL motif for rat dorsal root ganglion neurons. J. Biomed. Mater. Res. A 2010, 95, 1125-1131. 
18. Zhou, A.; Chen, S.; He, B.; Zhao, W.; Chen, X.; Jiang, D. Controlled release of TGF-beta 1 from RADA self-assembling peptide hydrogel scaffolds. Drug Des. Devel. Ther. 2016, 10, 30433051.

19. Wang, X.; Wang, J.; Guo, L.; Wang, X.; Chen, H.; Wang, X.; Liu, J.; Tredget, EE.; Wu, Y. Self-assembling peptide hydrogel scaffolds support stem cell-based hair follicle regeneration. Nanomedicine 2016, 12, 2115-2125.

20. Chen, K.; Sahoo, S.; He, P.; Ng, KS.; Toh, SL.; Goh, JC. A hybrid silk/RADA-based fibrous scaffold with triple hierarchy for ligament regeneration. Tissue Eng. Part A 2012, 18, 1399-1409. 21. Liedmann, A.; Frech, S.; Morgan, PJ.; Rolfs, A.; Frech, MJ. Differentiation of human neural progenitor cells in functionalized hydrogel matrices. Biores. Open Access 2012, 1, 16-24.

22. Wu, Y.; Jia, Z.; Liu, L.; Zhao, Y.; Li, H.; Wang, C.; Tao, H.; Tang, Y.; He, Q.; Ruan, D. Functional Self-Assembled Peptide Nanofibers for Bone Marrow Mesenchymal Stem Cell Encapsulation and Regeneration in Nucleus Pulposus. Artif. Organs 2016, 40, 112-119.

23. Pan, H.; Hao, S.; Zheng, Q.; Li, J.; Zheng, J.; Hu, Z.; Yang, S.; Guo, X.; Yang, Q. Bone induction by biomimetic PLGA copolymer loaded with a novel synthetic RADA16-P24 peptide in vivo. Mater. Sci. Eng. C Mater. Biol. Appl. 2013, 33, 3336-3345.

24. Liu, X.; Wang, X.; Horii, A.; Wang, X.; Qiao, L.; Zhang, S.; Cui, FZ. In vivo studies on angiogenic activity of two designer self-assembling peptide scaffold hydrogels in the chicken embryo chorioallantoic membrane. Nanoscale 2012, 4, 2720-2727.

25. Ellis-Behnke, RG.; Liang, YX.; Tay, DK.; Kau, PW.; Schneider, GE.; Zhang, S.; Wu, W.; So, KF. Nano hemostat solution: immediate hemostasis at the nanoscale. Nanomedicine: Nanotechnology, Biology and Medicine 2006, 2, 207-215. 
26. Koutsopoulos, S.; Zhang, S. Two-layered injectable self-assembling peptide scaffold hydrogels for long-term sustained release of human antibodies. J. Control. Release 2012, 160, 451458.

27. Karavasili, C.; Spanakis, M.; Papagiannopoulou, D.; Vizirianakis, IS.; Fatouros, DG.; Koutsopoulos, S. Bioactive self-assembling lipid-like peptides as permeation enhancers for oral drug delivery. J. Pharm. Sci. 2015, 104, 2304-2311.

28. Nagai, Y.; Unsworth, LD.; Koutsopoulos, S.; Zhang, S. Slow release of molecules in selfassembling peptide nanofiber scaffold. J. Control. Release 2006, 115, 18-25.

29. Karavasili, C.; Komnenou, A.; Katsamenis, OL.; Charalampidou, G.; Kofidou, E.; Andreadis, D.; Koutsopoulos, S.; Fatouros, DG. Self-Assembling Peptide Nanofiber Hydrogels for Controlled Ocular Delivery of Timolol Maleate. ACS Biomater. Sci. Eng. 2017, 3, 3386-3394.

30. Yang, P.; Song, H.; Qin, Y.; Huang, P.; Zhang, C.; Kong, D.; Wang, W. Engineering Dendritic-Cell-Based Vaccines and PD-1 Blockade in Self-Assembled Peptide Nanofibrous Hydrogel to Amplify Antitumor T-Cell Immunity. Nano Lett. 2018, 18, 4377-4385.

31. Wang, W.; Song, H.; Zhang, J.; Li, P.; Li, C.; Wang, C.; Kong, D.; Zhao, Q. An injectable, thermosensitive and multicompartment hydrogel for simultaneous encapsulation and independent release of a drug cocktail as an effective combination therapy platform. J. Control. Release. 2015, $203,57-66$.

32. Cai, Y.; Shen, H.; Zhan, J.; Lin, M.; Dai, L.; Ren, C.; Shi, Y.; Liu, J.; Gao, J.; Yang, Z. Supramolecular "Trojan Horse" for Nuclear Delivery of Dual Anticancer Drugs. J. Am. Chem. Soc. 2017, 139, 2876-2879. 
33. Kang, L.; Gao, Z.; Huang, W.; Jin, M.; Wang, Q. Nanocarrier-mediated co-delivery of chemotherapeutic drugs and gene agents for cancer treatment. Acta Pharm. Sin. B 2015, 5, 169175.

34. Wang, L.; Wang, W.; Rui, Z.; Zhou, D. The effective combination therapy against human osteosarcoma: doxorubicin plus curcumin co-encapsulated lipid-coated polymeric nanoparticulate drug delivery system. Drug Deliv. 2016, 23, 3200-3208.

35. Cui, T.; Zhang, S.; Sun, H. Co-delivery of doxorubicin and $\mathrm{pH}$-sensitive curcumin prodrug by transferrin-targeted nanoparticles for breast cancer treatment. Oncol. Rep. 2017, 37, 1253-1260.

36. Li, WM.; Chiang, CS.; Huang, WC.; Su, CW.; Chiang, MY.; Chen, JY.; Chen, SY. Amifostine-conjugated $\mathrm{pH}$-sensitive calcium phosphate-covered magnetic-amphiphilic gelatin nanoparticles for controlled intracellular dual drug release for dual-targeting in HER-2overexpressing breast cancer. J. Control. Release 2015, 220, 107-118.

37. Fang, JH.; Lai, YH.; Chiu, TL.; Chen, YY.; Hu, SH.; Chen, SY. Magnetic core-shell nanocapsules with dual-targeting capabilities and co-delivery of multiple drugs to treat brain gliomas. Adv. Healthc. Mater. 2014, 3, 1250-1260.

38. Yan, T.; Li, D.; Li, J.; Cheng, F.; Cheng, J.; Huang, Y.; He, J. Effective co-delivery of doxorubicin and curcumin using a glycyrrhetinic acid-modified chitosan-cystamine-poly $(\varepsilon-$ caprolactone) copolymer micelle for combination cancer chemotherapy. Colloids Surf. B Biointerfaces 2016, 145, 526-538.

39. Lv, L.; Qiu, K.; Yu, X.; Chen, C.; Qin, F.; Shi, Y.; Ou, J.; Zhang, T.; Zhu, H.; Wu, J.; Liu, C.; Li, G. Amphiphilic copolymeric micelles for doxorubicin and curcumin Co-delivery to reverse multidrug resistance in breast cancer. J. Biomed. Nanotechnol. 2016, 12, 973-985. 
40. Li, H.; Li, M.; Chen, C.; Fan, A.; Kong, D.; Wang, Z.; Zhao, Y. On-demand combinational delivery of curcumin and doxorubicin via a pH-labile micellar nanocarrier. Int. J. Pharm. 2015, $495,572-578$.

41. Sarisozen, C.; Dhokai, S.; Tsikudo, EG.; Luther, E.; Rachman, IM.; Torchilin, VP. Nanomedicine based curcumin and doxorubicin combination treatment of glioblastoma with scFvtargeted micelles: In vitro evaluation on 2D and 3D tumor models. Eur. J. Pharm. Biopharm. 2016, $10,8,54-67$.

42. Barui, S.; Saha, S.; Mondal, G.; Haseena, S.; Chaudhuri, A. Simultaneous delivery of doxorubicin and curcumin encapsulated in liposomes of pegylated RGDK-lipopeptide to tumor vasculature. Biomaterials. 2014, 35, 1643-1656.

43. Krauze, MT.; Noble, CO.; Kawaguchi, T.; Drummond, D.; Kirpotin, DB.; Yamashita, Y.; Kullberg, E.; Forsayeth, J.; Park, JW.; Bankiewicz, KS. Convection-enhanced delivery of nanoliposomal CPT-11 (irinotecan) and PEGylated liposomal doxorubicin (Doxil) in rodent intracranial brain tumor xenografts. Neuro. Oncol. 2007, 9, 393-403.

44. Karaca, M.; Dutta, R.; Ozsoy, Y.; Mahato, RI. Micelle mixtures for co-administration of gemcitabine and GDC-0449 to treat pancreatic cancer. Mol. Pharm. 2016, 13, 1822-32.

45. Zhu, R.; Wu, X.; Xiao, Y.; Gao, B.; Xie, Q.; Liu, H.; Wang, S. Synergetic effect of SLNcurcumin and LDH-5-Fu on SMMC-7721 liver cancer cell line. Cancer. Biother. Radiopharm. 2013, 28, 579-87.

46. Zhang, Y.; Zhang, H.; Wang, X.; Wang, J.; Zhang, X.; Zhang, Q. The eradication of breast cancer and cancer stem cells using octreotide modified paclitaxel active targeting micelles and salinomycin passive targeting micelles, Biomaterials, 2012, 33, 679-691. 
47. Fan, Y.; Du, W.; He, B.; Fu, F.; Yuan, L.; Wu, H.; Dai, W.; Zhang, H.; Wang, X.; Wang, J.; Zhang, X.; Zhang, Q. The reduction of tumor interstitial fluid pressure by liposomal imatinib and its effect on combination therapy with liposomal doxorubicin, Biomaterials, 2013, 34, 2277-2288. 48. Zhang, J.; Miao, L.; Guo, S.; Zhang, Y.; Zhang, L.; Satterlee, A.; Kim, WY.; Huang, L. Synergistic anti-tumor effects of combined gemcitabine and cisplatin nanoparticles in a stromarich bladder carcinoma model. J. Control. Release 2014, 182, 90-96.

49. Shen, W.; Chen, X.; Luan, J.; Wang, D.; Yu, L.; Ding, J. Sustained Codelivery of Cisplatin and Paclitaxel via an Injectable Prodrug Hydrogel for Ovarian Cancer Treatment. ACS Appl. Mater. Interfaces. 2017, 9, 40031-40046.

50. Lv, Q.; He, C.; Quan, F.; Yu, S.; Chen, X. DOX/IL-2/IFN- $\gamma$ co-loaded thermo-sensitive polypeptide hydrogel for efficient melanoma treatment. Bioact. Mater. 2017, 3, 118-128.

51. Wu, X.; Wu, Y.; Ye, H.; Yu, S.; He, C.; Chen, X. Interleukin-15 and cisplatin co-encapsulated thermosensitive polypeptide hydrogels for combined immuno-chemotherapy. J. Control. Release. 2017, 255, 81-93.

52. Yang, LJ.; Zhang, C.; Ren, C.; Liu, J.; Zhang, Y.; Wang, J.; Huang, F.; Zhang, L.; Liu, J. A Supramolecular Hydrogel Based on Chlorambucil and Peptide Drug for Cancer Combination Therapy. ACS Appl. Mater. Interfaces. 2018, doi: 10.1021/acsami.8b18425.

53. Cao, H.; Yang, Y.; Shao, Z. Doxorubicin hydrochloride and curcumin loaded silk fibroin/hydroxypropyl cellulose hydrogels for localized chemotherapy of cancer. J. Control. Release. 2015, 213, e39.

54. Yang, WJ.; Zhou, P.; Liang, L.; Cao, Y.; Qiao, J.; Li, X.; Teng, Z.; Wang, L. NanogelIncorporated Injectable Hydrogel for Synergistic Therapy Based on Sequential Local Delivery of 
Combretastatin-A4 Phosphate (CA4P) and Doxorubicin (DOX). ACS Appl. Mater. Interfaces. 2018, 10, 18560-18573.

55. Majumder, P.; Baxa, U.; Walsh, STR.; Schneider, JP. Design of a Multicompartment Hydrogel that Facilitates Time-Resolved Delivery of Combination Therapy and Synergized Killing of Glioblastoma. Angew. Chem. Int. Ed. Engl. 2018, 57, 15040-15044.

56. Zhang, H.; Tian, Y.; Zhu, Z.; Xu, H.; Li, X.; Zheng, D.; Sun, W. Efficient antitumor effect of co-drug-loaded nanoparticles with gelatin hydrogel by local implantation. Sci. Rep. 2016, 6, 26546.

57. Yun, Q.; Wang, SS.; Xu, S.; Yang, JP.; Fan, J.; Yang, LL.; Chen, Y.; Fu, SZ.; Wu, JB. Use of 5-Fluorouracil Loaded Micelles and Cisplatin in Thermosensitive Chitosan Hydrogel as an Efficient Therapy against Colorectal Peritoneal Carcinomatosis. Macromol. Biosci. 2017, 17. doi: 10.1002/mabi.201600262.

58. Nagahama, K.; Kawano, D.; Oyama, N.; Takemoto, A.; Kumano, T.; Kawakami, J. Selfassembling polymer micelle/clay nanodisk/doxorubicin hybrid injectable gels for safe and efficient focal treatment of cancer. Biomacromolecules. 2015, 16, 880-889.

59. Shen, W.; Chen, X.; Luan, J.; Wang, D.; Yu, L.; Ding, J. Sustained Codelivery of Cisplatin and Paclitaxel via an Injectable Prodrug Hydrogel for Ovarian Cancer Treatment. ACS Appl Mater Interfaces. 2017, 9, 40031-40046.

60. Ritger, P.L.; Peppas, N.A. A simple equation for description of solute release ii. Fickian and anomalous release from swellable devices. J. Control. Release. 1987, 5, 37-42.

61. Zhang, Y.; Huo, M.; Zhou, J.; Zou, A.; Li, W.; Yao, C.; Xie. S. DDSolver: an add-in program for modeling and comparison of drug dissolution profiles. AAPS J. 2010, 12, 263-71. 
62. Yushkevich, PA.; Piven, J.; Hazlett, HC.; Smith, RG.; Ho, S.; Gee, JC.; Gerig, G. User-guided 3D active contour segmentation of anatomical structures: significantly improved efficiency and reliability. Neuroimage. 2006, 31, 1116-1128.

63. McGee-Russell SM. Histochemical methods for calcium. J Histochem Cytochem 1958, 6, 2242.

64. Li, IC.; Moore, AN.; Hartgerink, JD. "Missing Tooth" Multidomain Peptide Nanofibers for Delivery of Small Molecule Drugs. Biomacromolecules. 2016, 17, 2087-2095.

65. Karavasili, C.; Panteris, E.; Vizirianakis, IS.; Koutsopoulos, S.; Fatouros, DG. Chemotherapeutic delivery from a self-Assembling peptide nanofiber hydrogel for the management of glioblastoma. Pharm Res. 2018, 35, 166.

66. Sivanantham, B.; Sethuraman, S.; Krishnan, UM. Combinatorial Effects of Curcumin with an Anti-Neoplastic Agent on Head and Neck Squamous Cell Carcinoma Through the Regulation of EGFR-ERK1/2 and Apoptotic Signaling Pathways. ACS Comb. Sci. 2016, 18, 22-35.

67. Chou, TC. Theoretical basis, experimental design, and computerized simulation of synergism and antagonism in drug combination studies. Pharmacol. Rev. 2006, 58, 621-681.

68. Elmore, S. Apoptosis: a review of programmed cell death. Toxicol. Pathol. 2007, 35, 495-516. 69. Filippi-Chiela, EC.; Oliveira, MM.; Jurkovski, B.; Callegari-Jacques, SM.; da Silva, VD.; Lenz, G. Nuclear morphometric analysis (NMA): screening of senescence, apoptosis and nuclear irregularities. PLoS One. 2012, 7, e42522.

70. Abe, T.; Fukamachi, Y.; Kanazawa, Y.; Furukawa, H.; Shimizu, K.; Hirano, T.; Kasai, H.; Kashimura, M.; Higashi, K. Inhibition of nucleolar function and morphological change by adriamycin associated with heat shock protein 70 accumulation. Jpn. J. Cancer Res. 1996, 87, 945951. 
71. Barlogie, B.; Drewinko, B.; Johnston, DA.; Freireich, EJ. The effect of adriamycin on the cell cycle traverse of a human lymphoid cell line. Cancer Res. 1976, 36, 1975-1979.

72. Stravopodis, DJ.; Karkoulis, PK.; Konstantakou, EG.; Melachroinou, S.; Lampidonis, AD.; Anastasiou, D.; Kachrilas, S.; Messini-Nikolaki, N.; Papassideri, IS.; Aravantinos, G.; Margaritis, LH.; Voutsinas, GE. Grade-dependent effects on cell cycle progression and apoptosis in response to doxorubicin in human bladder cancer cell lines. Int. J. Oncol. 2009, 34, 137-160.

73. Boatright, KM.; Salvesen GS. Mechanisms of caspase activation. Curr. Opin. Cell Biol. 2003, $15,725-731$.

74. Song, H.; Han, Y-Z.; Cai, G-H.; Tang, F-S.; Yang, Z-H.; Ao, D-S.; Zhou, A. The effects of self-assembling peptide RADA16 hydrogel on malignant phenotype of human hepatocellular carcinoma cell. Int. J. Clin. Exp. Med. 2015, 8, 14906-14915.

75. Bailey, SA.; Zidell, RH.; Perry, RW. Relationships between organ weight and body/brain weight in the rat: what is the best analytical endpoint? Toxicol. Pathol. 2004, 32, 448-466.

76. Macklin, P.; Mumenthaler, S.; Lowengrub, J. (2013) Modeling multiscale necrotic and calcified tissue biomechanics in cancer patients: application to ductal carcinoma in situ (DCIS). In: Gefen A. (eds) Multiscale Computer Modeling in Biomechanics and Biomedical Engineering. Studies in Mechanobiology, Tissue Engineering and Biomaterials, vol 14. Springer, Berlin, Heidelberg

77. Wallace, DI.; Guo, X. Properties of tumor spheroid growth exhibited by simple mathematical models. Front Oncol. 2013, 3, 51.

78. Macklin, P.; Edgerton, ME.; Thompson, AM.; Cristini, V. Patient-calibrated agent-based modelling of ductal carcinoma in situ (DCIS): from microscopic measurements to macroscopic predictions of clinical progression. J Theor Biol. 2012, 301, 122-140. 
79. Bogovic, JA.; Hanslovsky, P.; Wong, A.; Saalfeld, S. "Robust registration of calcium images by learned contrast synthesis", In: Biomedical Imaging (ISBI), 2016 IEEE 13th International Symposium on, 1123-1126, DOI: 10.1109/ISBI.2016.7493463. 